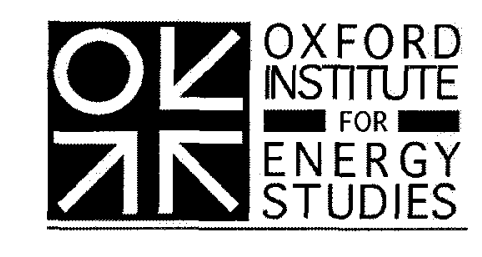

\title{
Seeking the Single European Electricity Market
}

Evidence From an Empirical Analysis of Wholesale Market Prices

John Bower

Oxford Institute for Energy Studies

EL 01

July 2002 


\section{Seeking the Single European Electricity Market}

Evidence From an Empirical Analysis of Wholesale Market Prices

John Bower

Oxford Institute for Energy Studies

EL 01

July 2002 
The contents of this paper are the author's sole responsibility. They do not necessarily represent the views of the Oxford Institute for Energy Studies or any of its Members

\title{
Copyright $\odot 2002$ \\ Oxford Institute for Energy Studies
}

(Registered Charity, No. 286084)

\begin{abstract}
All rights reserved. No part of this publication may be reproduced, stored in a retrieval system, or transmitted in any form or by any means, electronic, mechanical, photocopying, recording. or otherwise, without prior permission of the Oxford institute for Energy Studies.

This publication is sold subject to the condition that it shall not, by way of trade or otherwise, be lent, resold, hired out, or otherwise circulated without the publisher's consent in any form or binding or cover other than that in which it is published and without similar condition including this condition being imposed on the subsequent purchaser.
\end{abstract}

ISBN 1091795217 


\section{CONTENTS}

\section{Page}

ABSTRACT

1. INTRODUCTION

1.1. EU Electricity Market Legislation 2

1.2. Retail Market Competition 3

2. BACKGROUND 6

2.1. European Electricity Transmission Networks 6

2.2. European Electricity Industry Structure $\quad 8$

2.3. Development of European Wholesale Electricity Markets 8

2.4. Transmission Tariffs 10

$\begin{array}{ll}\text { 2.5. Cross-border Trade } & 10\end{array}$

2.6. European Commission Proposals 15

3. ANALYSIS 16

3.1. Wholesale Locational Spot Market Prices 16

3.2. Correlation Analysis of Locational Price Changes 19

3.3. Cointegration Analysis of Locational Price Changes 19

4. DISCUSSION 24

4.1. Locational Spot Price Model 24

4.2. Evidence of Arbitrage From Physical Constraints and Flows 26

4.3. Evidence of Arbitrage From Correlation and Cointegration 27

4.4. Efficiency in Locational Spot Prices $\quad 28$

4.5. Efficiency in Pricing of Transmission Congestion 29

4.6. Efficiency in Pricing Transmission Losses 36

5. IMPLICATIONS 37

5.1. Increasing the Efficiency of Transmission Pricing Mechanisms 37

5.2. Transmission Investment 38

$\begin{array}{ll}\text { REFERENCES } & 40\end{array}$ 


\section{FIGURES}

Figure 1. EU percentage of electricity consumption eligible for supply competition

Figure 2a. EU retail electricity price for commercial/household consumers

Figure $2 \mathrm{~b} \quad$ EU retail electricity price for large industrial consumers

Figure 3. $\quad$ European transmission networks

Figure 4. EU generation capacity concentration ratio (3 Firm) in 2001

Figure 5. Day-ahead electricity prices on European exchange traded markets in 2001

\section{TABLES}

Table 1. Time series data

Table 2. Summary statistics for daily locational prices

Table 3. Correlation matrix of daily locational spot price changes in 2001

Table 4. ADF values from cointegration analysis of daily locational spot prices in 2001

Table 5. Estimated Lerner Index for European wholesale spot electricity markets in 2001

Table 6. Theoretical price of transmission congestion between European locations in 2001 


\section{ABSTRACT}

The objectives of this paper are to assess the progress made towards a single European wholesale electricity market by the end of 2001, and identify remaining sources of economic inefficiency. Statistical analysis of day-ahead prices, in fifteen European locations, show Nord Pool (Scandinavia), and German, wholesale markets were almost perfectly competitive, but frequent price spikes, and reversion to equilibrium levels above marginal generation costs, occurred elsewhere. Daily price changes were well correlated between Nord Pool locations, but not others. Cointegration analysis shows prices were well integrated between all locations, except Spain. Results are consistent with arbitrage trading between locations, and the existence of a single European electricity market. However, the market is inefficient because generating firms exercised market power at some locations, and mechanisms to allocate capacity on congested transmission lines were weak. The European Commission should increase competition by breaking up dominant generating firms, not subsidising transmission capacity construction.

\section{INTRODUCTION}

The Single European Act (EU, 1988) established the general principle of a single European 'internal market', rather than many separate national markets, for goods and services in the European Union (EU). The European Commission (EC) working document on the Internal Energy Market (EC, 1988) was published as a direct result, and led to a range of legislation being adopted throughout the 1990s that explicitly aimed to fully integrate the separate European national electricity markets, with the aim of increasing competition in the European electricity industry, and hence reduce prices being paid by consumers. The Price Transparency Directive (EU, 1990a) sought to promote competition by improving the transparency of electricity (and gas) prices charged to industrial consumers. The Electricity Transit Directive (EU, 1990b) and the Gas Transit Directive (EU, 1991) aimed to remove obstacles to cross-border exchange of electricity (and gas) by asking member states to facilitate transit through transmission grids, though it did not compel them to do so.

I would like to thank my colleagues at the OIES, for their suggestions and comments on earlier drafts of this paper. Also thanks to Katriana Juselius for her help with my cointegration queries, as well as Nord Pool, and UKPX, for giving me access to price data. All remaining errors and omissions are mine. 


\subsection{EU electricity market legislation}

However, it was only with the publication of the 1995 Green Paper on energy policy (EC, 1995) that energy market liberalisation in the EU gained real momentum. The objective was to provide the European Institutions with the basis for evaluating whether or not the Community had a greater role to play in energy. It was as a result of this debate that the Electricity Directive (ED) entered into force in February 1997 (EU, 1996b), along with the closely related Gas Directive (GD) in August 1998 (EU, 1998). Though these two pieces of legislation were only enabling, in the sense that they still had to be transposed into national law, and would therefore still be open to wide interpretation during the process of implementation, the necessary conditions for creating a single internal market for electricity throughout the EU were largely in place by the end of 2000. As well as liberalising markets, the EU was also concerned about expanding the existing infrastructure in energy networks, especially electricity (and gas) transmission systems, to promote competition, and integration, through a series of initiatives under the heading Trans-European Networks (TENs) (EU, 1996a). For a fuller discussion of EU energy legislation see, for example, Cini \& McGowan (1998), Bergman et al (1999), and Cameron (2002).

The ED established common rules for the generation, transmission, distribution, and supply sectors of the electricity supply industry in all EU countries. The principles established were (EC, 2000):

i. Unbundling of accounts to prevent subsidisation, and distortion of competition, in vertically integrated firms;

ii. Competition in construction of new plant, either via an authorisation procedure, allowing markets to determine investment criteria, or via a tendering procedure, allowing central planners to determine when, and where, to build capacity;

iii. Open access to transmission (and distribution) networks guaranteed by the mandatory appointment of an independent system operator (ISO) transparent, and non discriminatory carriage charges, with only reciprocity, and system reliability, allowing countries to bar entry; and

iv. Consumers having the right to choose their supplier with approximately $26.5 \%$ of total supply to be fully open to competition by February 1999, 28\% by February 2000 , and $33 \%$ by February 2003. 
Though not an explicitly stated objective, the EC goal was to use the ED to create conditions in which the coordinating role of state ownership, and central planning, could be challenged and eventually replaced by markets. Giving consumers the right to choose their own supplier was designed to stimulate competition in the retail market, while mandatory competitive tendering in the procurement of new generation capacity was the first step in creating wholesale markets where generators and suppliers would trade electricity as a bulk commodity.

\subsection{Retail Market Competition}

Figure 1 shows that, in many $\mathrm{EU}^{1}$ countries, supply competition in the retail market had developed more quickly than expected, as the percentage of customers free to choose their suppliers by 2001 was well ahead of the ED minimum benchmark. However, over half of the countries were below the new benchmark, agreed in March 2002 at the Barcelona European Council meeting, that all industrial consumers, and no less than $60 \%$ of each national market, would be eligible for supply competition by 2004 (European Council, 2002). Figure 2 compares EU electricity prices being paid by consumers during 1997, and 2001. Rapid introduction of supply competition had a significant impact in some countries with large industrial consumers enjoying a demand weighted price fall of $24.4 \%$, and household/small commercial consumers a $10.1 \%$ reduction across the EU. In Germany, which opened its market to full supply competition on 1 April 1998, mean annual prices for large industrial consumers fell by $42.8 \%$ during the period $1997-2001$, with most of that reduction occurring in 1998. Though the European electricity industry responded by cutting overheads, after prices began to fall, marginal generation costs were stable or rising with European steam coal $^{2}$ import prices up 1.4\%, and natural gas ${ }^{3}$ import price up 28\%, between 1997 and 2001. Overall, retail prices therefore appear to have fallen due to an increase in competition, rather than lower input costs. Large industrial consumers saw the greatest benefit, mainly because they had all been eligible for supply competition longer than commercial/household consumers.

\footnotetext{
${ }^{1}$ There were 15 member states of the EU as at 31 December 2001. Norway narrowly rejected joining in 1995 but had a fully liberalised electricity market, and traded with EU countries so is notionally included in the EU market here.

${ }^{2}$ Arithmetic mean of first reported monthly price (US\$) 1997 and 2001 of McCloskey Coal: MCIS Steam Coal Index NEW.

${ }^{3}$ Arithmetic mean of all reported European natural gas prices (US\$) in 1997 and 2001 from Heren Report - Border prices.
} 
Figure 1: EU percentage of electricity consumption eligible for supply competition

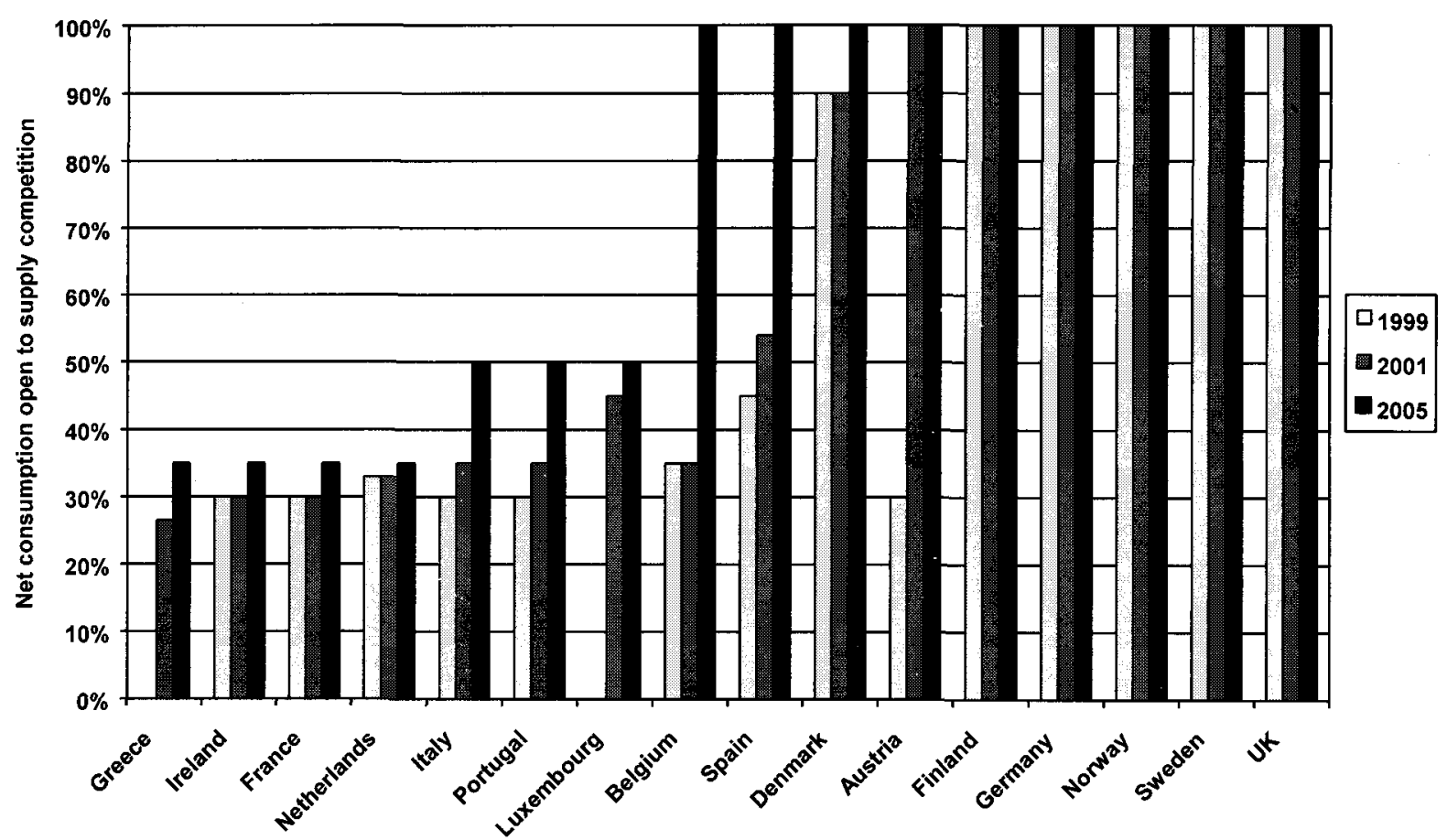

Though retail prices had clearly fallen since 1997 it is striking that, even among large industrial consumers, where competition was most intense, there was still a wide variation in prices between countries during 2001. For example, the price in Norway, at $29.0 € / \mathrm{MWh}$ ), was some $71 \%$ lower than the price in Austria, at $99.6 € / \mathrm{MWh}$ ). It is clear that many countries still had a long way to go to reach the EU weighted average of $€ 56 / \mathrm{MWh}$, for large industrial consumers, let alone the competitive levels seen across Scandinavia. Meanwhile, most household/small commercial consumers, in most EU countries, had still seen little benefit. Despite the apparent progress that had been made in implementing the ED, ahead of schedule in many countries, in a report marking the fourth anniversary of the ED (EC, 2001b) the EC concluded that the European electricity market was still not fully competitive and consumers were paying higher prices than necessary. The main causes identified were:

$i$. Excessive network tariffs which were a barrier to third party entry;

ii. High levels of market power which still existed in the generation sector;

iii. Illiquid wholesale markets which exposed new entrants to severe price risk;

$i v$. Network tariffs not published in advance, which lead to costly disputes; and

$v$. Insufficient unbundling of vertically integrated generation, transmission, distribution, and supply sectors that had allowed discriminatory charges, and cross-subsidies. 
Figure 2a: EU retail electricity price for commercial/household consumers

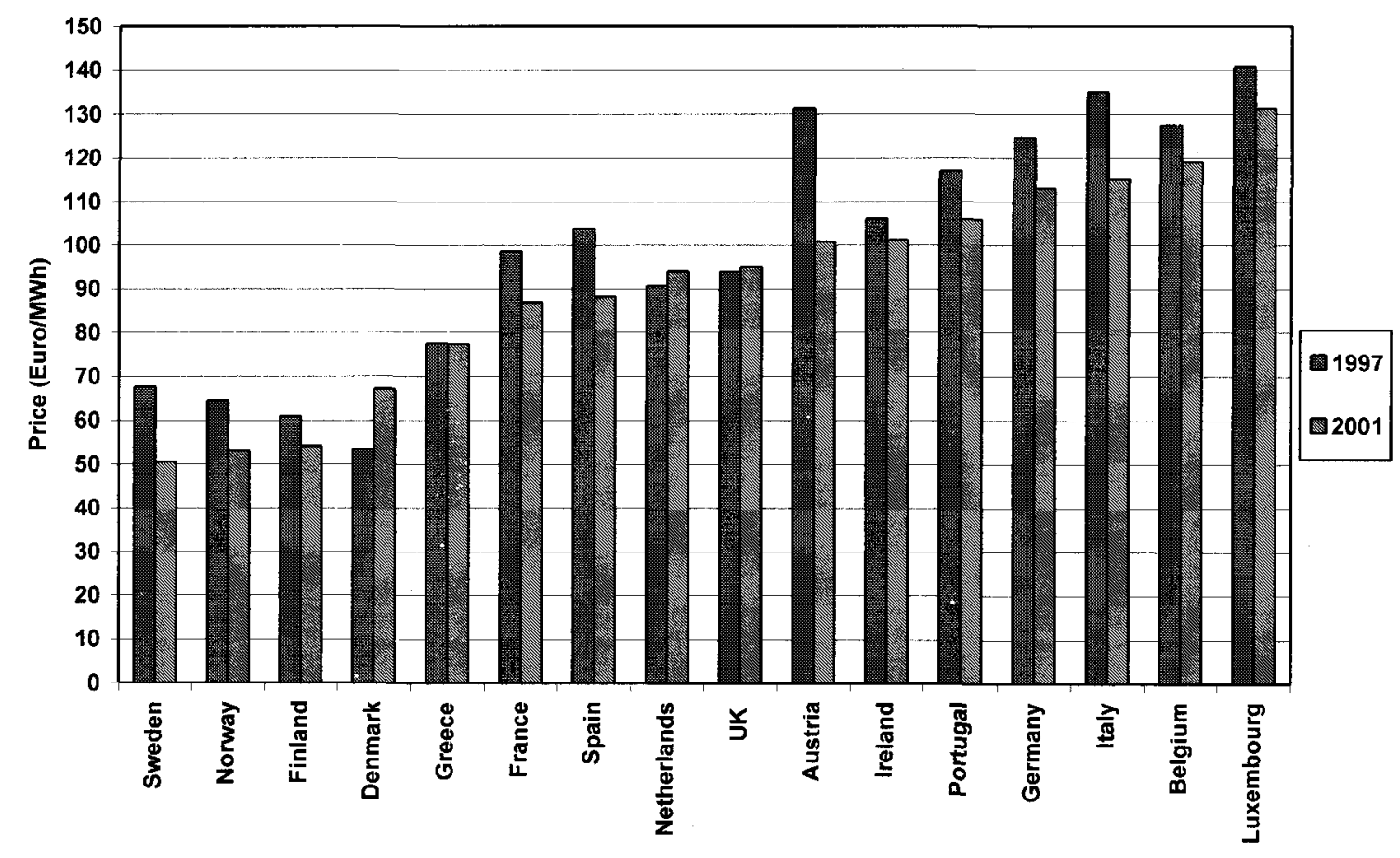

Source: Eurostat: Average of Jan and July lb industrial and Dd domestic consumer prices

Figure 2b: EU retail electricity price for large industrial consumers

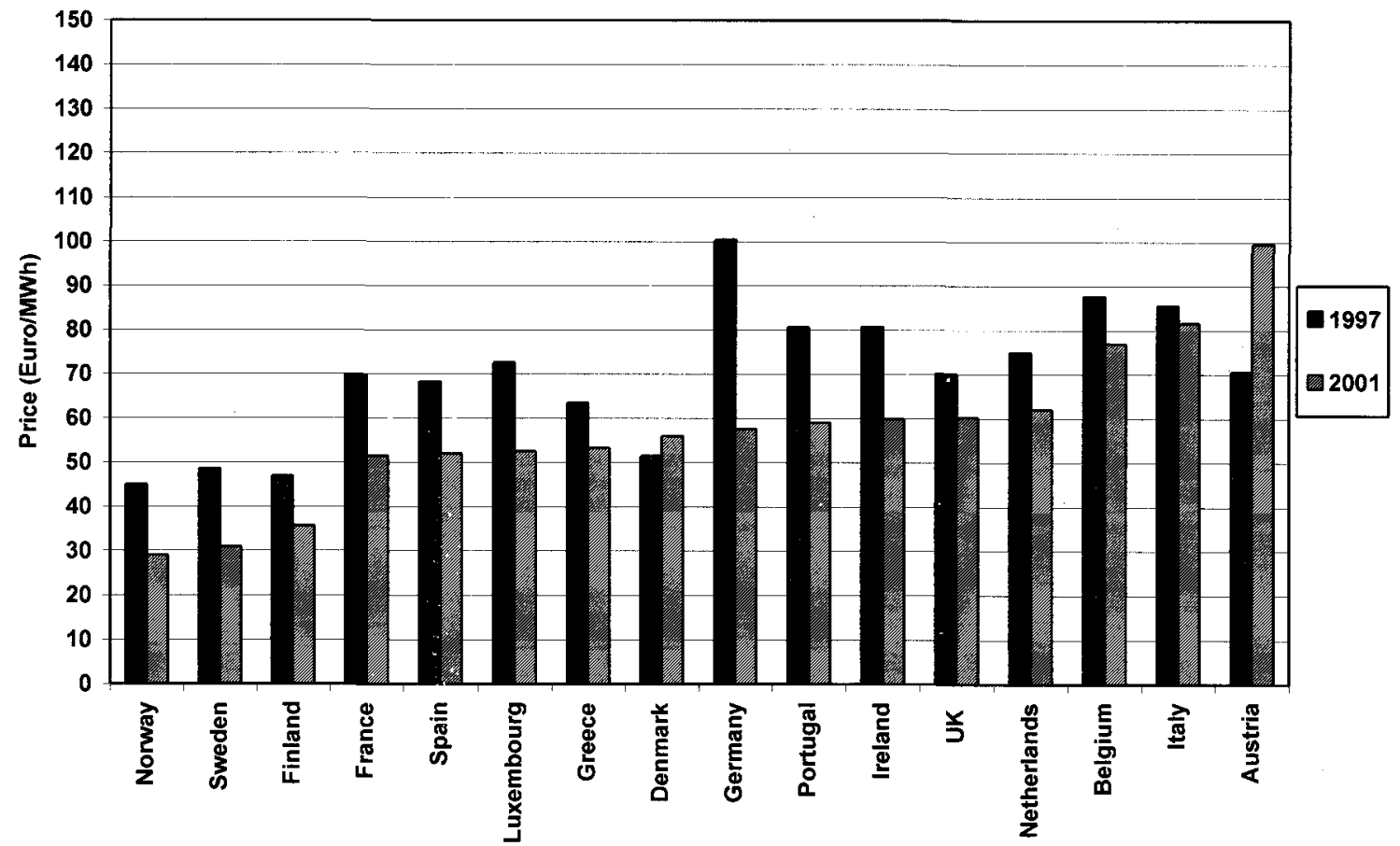

Source: Eurostat: Average of Jan and July le and lg industrial consumer prices except Austria is average of Jan and July Ic price, Luxembourg is average of Jan $2001 \mathrm{lg}$ and le price only, UK and Denmark 2001 price is average of Jan and July le price only, Netherlands 2001 price is average of July 2001 le and lg price only 
The primary objectives of this paper are to assess the progress that had been made towards a single European wholesale electricity market, by the end of 2001, and identify what remaining sources of economic inefficiency remained to be addressed. In the next section, the background to European electricity market liberalisation is briefly discussed. Then correlation, and cointegration, analysis are applied to mean daily spot (day-ahead) wholesale market price time series data collected from European electricity exchanges operating in Germany, Netherlands, Scandinavia, Spain, and the UK, during 2001. The level of integration already achieved between locational spot electricity markets across Europe is assessed. In section four, the results are discussed, and the efficiency of locational spot prices, and transmission costs, are benchmarked against a theoretical locational marginal price model. Finally, EC proposals to complete the single European electricity market are reviewed in light of the analysis.

\section{BACKGROUND}

This section describes how the industry evolved both before, and after, the ED was implemented, including the development of the industry structure, transmission systems, transmission tariffs, wholesale markets, and cross-border import-export trade.

\subsection{European Electricity Transmission Networks}

The European electricity transmission system developed over many decades as a patchwork of transmission systems owned, and operated, by over 40 different transmission system operators (TSOs). Each TSO was a member of one of four Regional Transmission Organisations (RTOs), ${ }^{4}$ as shown in Figure 3, within which they agreed to coordinate their activities, and effectively operate their capacity as a single fully synchronised alternating current (AC) network to common reliability standards. The four European RTOs operated independently of each other (asynchronously) but were connected by direct current (DC) sub sea cables that allowed transfers of electricity to be made between them. With the encouragement of the EC, the four RTOs formed the European Transmission System Operators (ETSO) forum, in 2001, to support the continued development of the single

${ }^{4}$ TSOI, the association of TSOs in Ireland; UKTSOA, the United Kingdom TSO association; NORDEL, the Nordic TSOs, UCTE, the Union for the Coordination of Transmission of Electricity. CENTREL, a fifth RTO covering Poland, Hungary, Czech Republic, Slovakia, synchronised with the UCTE in 1999, and joined ETSO in 2002 . 
European electricity market by facilitating cross-border trade in electricity within the EU, as well as with other European countries outside the EU.

Figure 3: European transmission networks

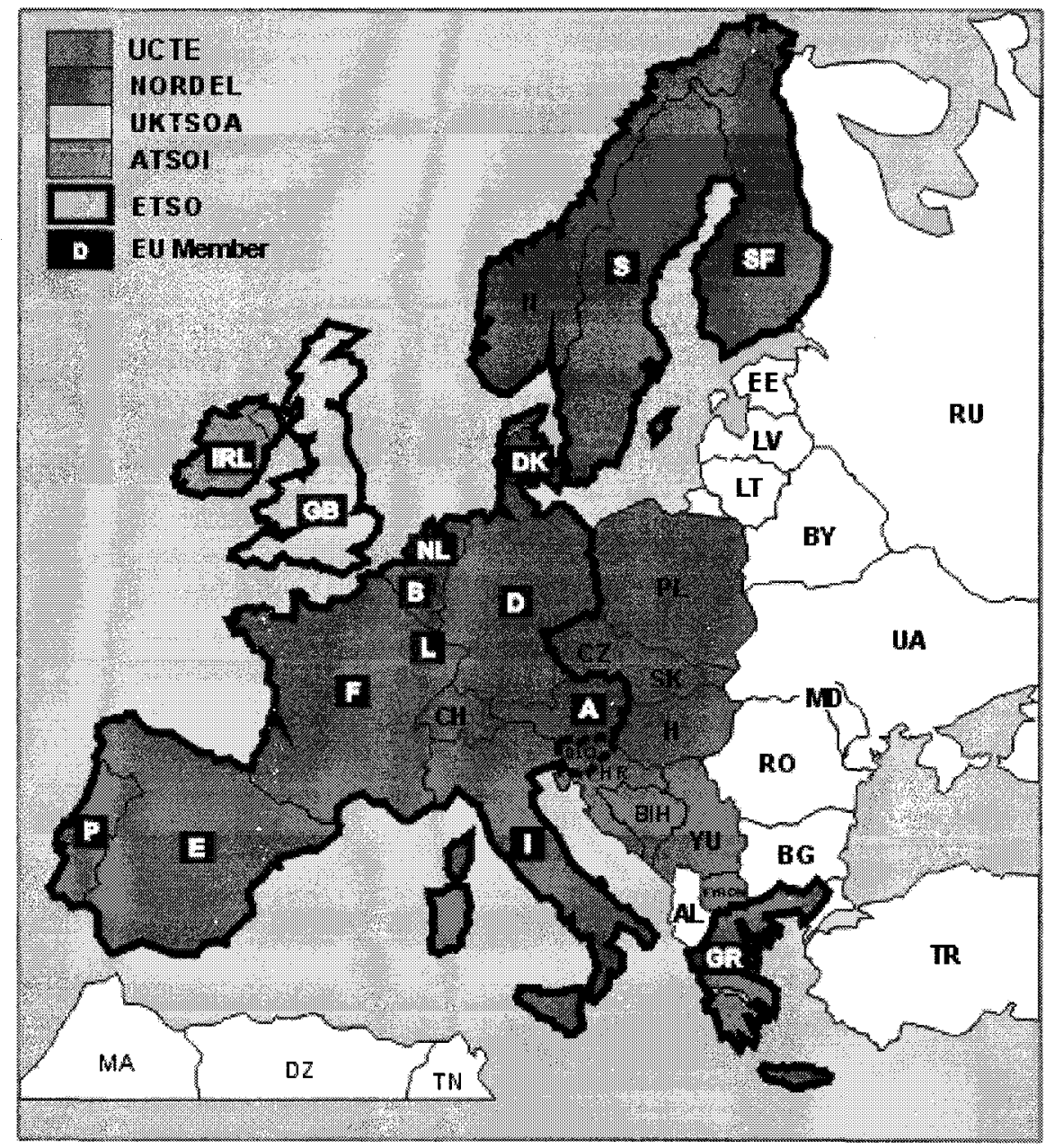

Source: Used with permission of the UCTE

Prior to 1997, most European countries had adopted energy security policies with the explicit objective of remaining self sufficient in electricity. Where cross-border import-export flows occurred these were usually managed through a series of bilateral cooperation agreements between countries that effectively limited trade to reciprocal swaps of equal quantities of energy at different times of day, or between different seasons of the year, and to provide emergency back-up supplies in case of system failure. Some long-term supply agreements did exist (e.g. France $\rightarrow$ Italy), usually negotiated at the ministerial level. After 1997, crossborder contracting between generators, and consumers in different countries became possible, but net physical cross-border flows only increased by 1-2\% over the period 1997-2001. Cross-border flows, still only accounted for only $8 \%$ of EU net electricity consumption in 
2001. This was regarded by the EC as a strong indication that Europe still operated as a collection of isolated national electricity markets, rather than an integrated single European electricity market. For historical reasons, cross-border grid interconnections had always been less well developed than those within countries, and the EC noted that, even in 2001, the system was still effectively operating as a core network in mainland Western Europe, surrounded by six islands of electrical activity: the United Kingdom, the island of Ireland, Scandinavia, Iberia, Italy and Greece (EC, 2001c).

\subsection{European Electricity Industry Structure}

When the ED was introduced, vertically integrated firms with monopoly rights to supply electricity to an entire country, state, or municipality still populated the electricity supply industry in most EU countries. Most of these firms were also fully owned, and controlled, by central, or local government. The ED gave no direction as to how supply competition should be introduced, and many countries simply left their industry structure unchanged. Though some EU countries had broken up, and then privatised, their national monopoly electricity supply industry, in the late 1990s, it had quickly reconsolidated through mergers. As shown in Figure 4, the generation sector was still highly concentrated in most countries, during 2001, with at least partial vertical integration between generation, transmission, distribution, and supply sectors, remaining. As the transmission, and distribution, sectors continued to operate as natural monopolies, firms therefore had significant opportunities to exercise market power. This was especially true where they were able to exploit barriers to entry created by bottlenecks (constraints) in the cross-border transmission system that prevented competitively priced supplies from being imported from other countries. Since the ED allowed TSOs to curtail flows that would otherwise threaten network reliability, it had proved almost impossible for regulators to determine whether a vertically integrated TSO has curtailed access as a form of anti-competitive behaviour or whether they have done so for legitimate reasons.

\subsection{Development of European Wholesale Electricity Markets}

Two wholesale spot electricity markets were in existence in Europe before 1997. The England \& Wales Pool, replaced in March 2001 by a bilateral market called New Electricity Trading Arrangements (NETA), and the Nord Pool that was gradually extended, throughout 
the 1990s, to cover the four Scandinavian countries of Norway, Sweden, Finland and Denmark. Both of these markets had operated as organised electronic commodity exchanges, since 1990. However, in response to the wave of electricity market liberalisation created by the ED more informal over-the-counter (OTC) markets began to appear to trade electricity for delivery in other European locations, during 1998. Operating over the telephone via brokers, or on Internet bulletin boards, price transparency in these OTC markets was poor, and liquidity low, often with one or two large firms effectively setting the closing price every day.

Figure 4: EU generation capacity concentration ratio (3 Firm) in 2001

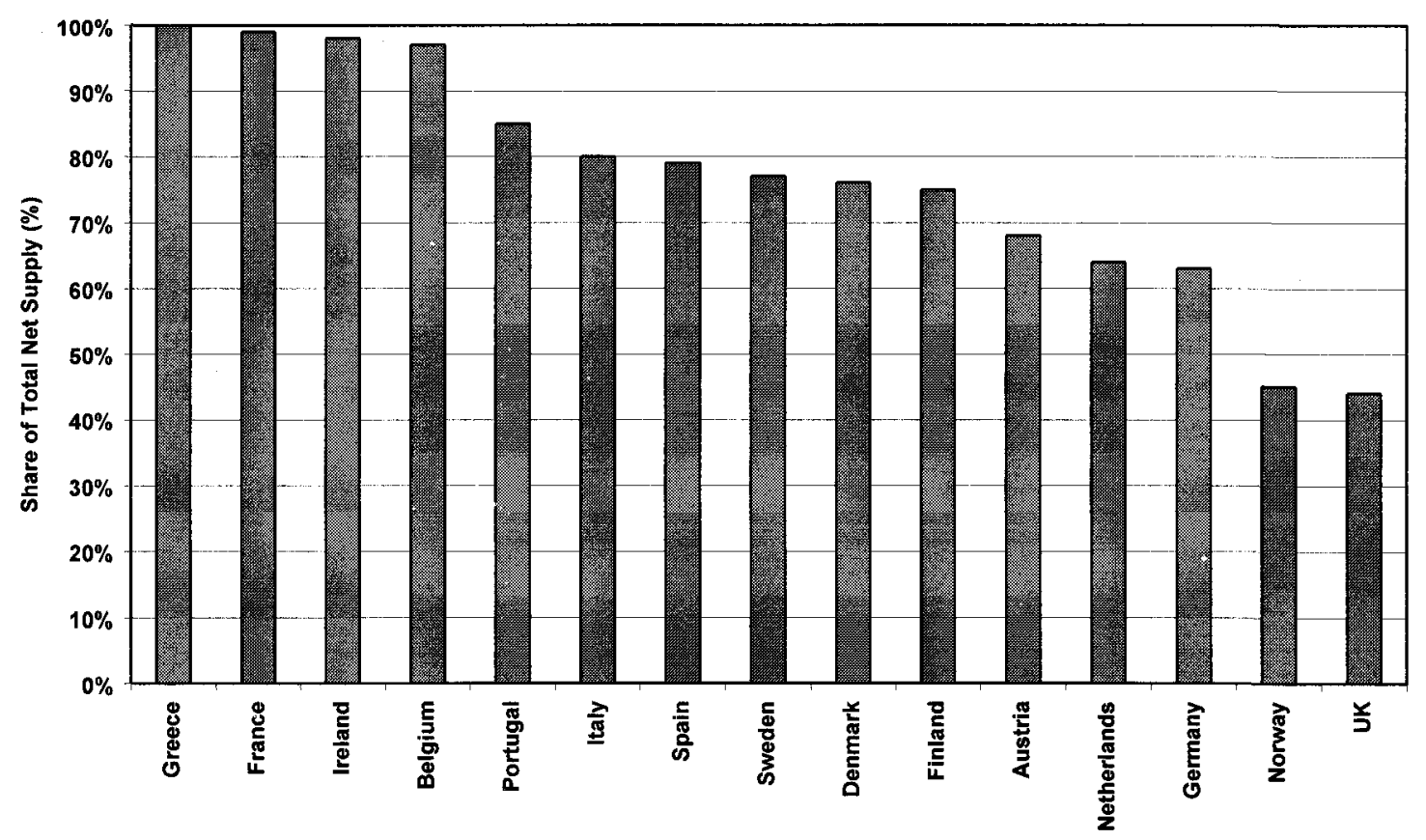

Source: European Commission and own calculations

The development of exchange traded electricity markets initially lagged that of OTC markets, but in 1998 Spain instituted a pool-based market, similar to that in England \& Wales, and in June 1999 the Netherlands began operating the Amsterdam Power Exchange (APX). Two further exchange traded electricity markets began operating in Germany during 2000, the Leipzig Power Exchange (LPX), and the European Energy Exchange (EEX), which eventually merged in December 2001. France began operating an organised electricity exchange, PowerNext, in November 2001. The Austrian power exchange (EXAA) opened in March 2002. By early 2002, discussions, detailed plans, and in some cases investment in electronic infrastructure, had also taken place to establish exchange traded electricity markets 
in Greece, Ireland, Italy, Poland, and Portugal, though the date at which they would begin operation still depended on legislative, and regulatory progress.

\subsection{Transmission Tariffs}

Prior to 1997 , the energy and transmission cost of electricity to consumers, both within and between countries, was generally combined in a single fixed tariff. Once the ED came into force, mandatory transmission access rights made it necessary to price energy separately from transmission. The level at which transmission tariffs were set was left to each individual country to determine. In some countries, a regulator oversaw this, but incumbent TSOs had a significant influence on the design of access rules, and tariff structures, because they were the only source of operational, and cost data. As well as exploiting physical constraints, vertically integrated firms therefore had the incentive, and the means, to ensure that the design of the transmission (and distribution) tariff structure effectively raised the price of electricity imported from outside their own network, hence making it less competitive against electricity produced by their own generating businesses. Even where regulatory intervention had prevented tariffs being applied in a discriminatory fashion, for example by mandating identical tariffs for imported, and own produced electricity, any revenue lost by the generation business of a vertically integrated firm could still be cross-subsidised by gains from increased tariffs in the transmission business.

\subsection{Cross-border Trade}

Though the ED had established the general principle of open access to cross-border transmission capacity, there was no regulatory oversight of cross-border trade, and most contracts signed after 1997 simply assumed that electricity flowed along the shortest route, between a generator, and consumer, and therefore that a contract could be struck with the TSOs along that route to transit the electricity. In practice, this 'contract path' method gave rise to pancaking of transmission tariffs as each TSO charged both an entry, and exit, fee to their systems. As far as the EC was concerned this pancaking presented an obvious barrier to trade, and the completion of the internal market, because it effectively discriminated in favour of indigenous generating firms by making import-export trade in electricity prohibitively expensive. For example, a German generator wishing to sell electricity to a large industrial consumer in Spain, while technically allowed to do so under the ED, would 
have found it difficult to compete with indigenous Spanish generators because it would have to pay a transmission tariff in Germany, France, and Spain.

The contract path method also failed to take account of the impact of 'loop flow', a very well understood phenomenon inherent in the operation of $\mathrm{AC}$ networks. As a result of the liberalisation of cross-border trade, brought about by the ED, TSOs had increasingly found their networks becoming congested by parallel flows, from other countries, and that they were effectively providing capacity for which they could not be compensated because they were not on the contract path between the parties responsible for creating the flows. This also threatened system security as, for example, had happened on 14 July 1999, which is the Bastille day holiday in France (UCTE, 2002). With French demand low, output from Electricité de France (EDF) nuclear power plants was sold into Germany, where it was a normal working day, but a significant proportion of the power did not flow on transmission lines along the contract path crossing the France-Germany border but along a parallel path through France-Belgium-Germany. This resulted in the Belgian transmission system becoming so overloaded that if a single line had failed it would have caused a major blackout that, because of the interconnected nature of the UCTE grid, could have extended across North West Europe. However, as EDF was using the contract path assumption, it did not purchase any transmission capacity from ELIA, the Belgian TSO. As a result, ELIA were unaware of the potential cross-border flows until the day they occurred, and were not compensated for use of their transmission system.

The EC set up the European Electricity Regulatory Forum (EERF), which regularly met in Florence, to facilitate dialogue between ETSO, the EC, electricity firms, and national regulators. The issues that EERF was tasked with addressing were to develop:

i. $\quad$ tariffs to cover cross-border electricity import-export trade;

ii. methods to allocate scarce interconnection capacity between countries, and

iii. compensation mechanisms for TSOs in transit countries.

ETSO began by publishing a set of net transfer capacities (NTC) for each national border in Europe (ETSO, 1999). Developing a non-discriminatory method of charging for cross-border transmission capacity, and compensating TSOs for loop flow proved much more complex, and many compromise proposals came and went [for key references see EERF 2000-2002 
and ETSO 2000 - 2001]. Eventually, a temporary cross-border tariff agreement was reached, (ETSO, 2001d) to collect a $€ 200$ million fund that would be distributed to each TSO according to the amount of net flows that occurred through their network in the year. Any shortfall in the fund would be made up the following year. This would be collected via a $€ 1 / \mathrm{MWh}$ charge on generators' declared exports, and a $€ 1 / \mathrm{MWh}$ charge on net imports to each country, that would be socialised across consumers. This new system had the virtue of replacing the pancaking of import-export tariffs but the EC argued that the $€ 1 / \mathrm{MWh}$ charge was still too high, and that it would restrict cross-border trade. There was no agreement for 2003, and beyond, but the European Council urged that particular effort be made:

\footnotetext{
...to reach as early as possible in 2002 an agreement for a tariff-setting system for crossborder transactions in electricity, including congestion management, based on the principles of non-discrimination, transparency, and simplicity (European Council, 2002 )
}

This temporary ETSO compromise only addressed the issue of compensating transit countries for loop flow. It made no specific recommendations as to how scarce cross-border capacity should be allocated on congested routes, but left this to individual countries, and their TSOs, to resolve. However, the EC had concluded, in a variety of reports [see for example IAEW/Consentec (2001), and EC (2001a, 2001b, 2001c)] that there was insufficient physical transmission capacity between some EU countries, leading to physical constraints, which were preventing otherwise competitively priced electricity from being imported to meet demand. These studies identified the major cross-border transmission constraints on AC transmission lines within the coordinated RTO networks of Europe that were either permanently, or frequently, congested as:

$$
\begin{array}{ll}
\text { i. } & \text { Portugal } \leftrightarrow \text { Spain } \\
\text { ii. } & \text { France } \rightarrow \text { Spain; } \\
\text { iii. } & \text { France } \rightarrow \text { Belgium \& Belgium/Germany } \rightarrow \text { Netherlands } \\
\text { iv. } & \text { Austria } \rightarrow \text { Switzerland } \\
v . & \text { Denmark (West) } \leftrightarrow \text { Germany, } \\
\text { vi. } & \text { France/Switzerland/Austria } \rightarrow \text { Italy, and } \\
\text { vii. } & \text { Norway } \leftrightarrow \text { Sweden. }
\end{array}
$$


In addition, the EC had concluded that most of the DC lines that interconnected the separate RTO networks of Europe were also frequently, or permanently, operating at full capacity. The most important of these being:

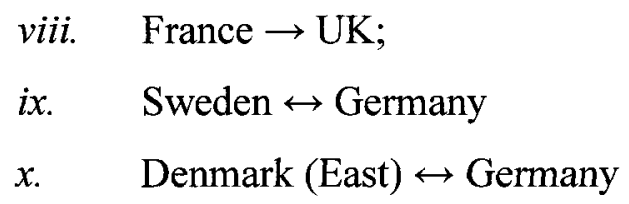

The second issue highlighted was that the mechanisms being used to allocate scarce capacity on congested cross-border lines varied widely across the EU. Within the UCTE, a series of bilateral agreements had developed between adjoining TSOs, that either gave priority to longterm contracts, struck before the ED was implemented, or allocated capacity on a first-comefirst served basis such as between France-Spain, France-Belgium, Austria-Italy. However, explicit auction mechanisms had been instituted in 2000-2001 to allocate cross-border capacity on the AC transmission network linking Germany-West Denmark, and GermanyBelgium-Netherlands. In the latter case, the total notional cross-border capacity available was reduced to take account of operational constraints, reliability constraints, and any long-term contracts signed before the ED was implemented. The remaining capacity was then distributed among the three adjoining borders, using fixed percentages, and finally allocated to six individual auctions, with the four adjoining TSOs jointly operating the auctions, and sharing the revenues. Although these capacity auctions did not allocate capacity on specific physical transmission lines, the mechanism employed still implicitly assumed that electricity flowed along a direct 'contract path' route between the countries concerned, and ignored loop flow. As a result the auction prices paid took no account of congestion caused by parallel flows on transmission lines not owned, or operated, by other TSOs not on the 'contract path'.

Regular auctions were introduced on the France-UK DC interconnector, in March 2001, allowing capacity to be purchased by any party, on a day-ahead, month-ahead or year-ahead basis via a regular series of sealed bid tenders. The auction was operated by the two TSOs, NGC in the UK, and RTE in France, who shared the revenue. Since loop flow does not occur on a DC transmission line, though it will still occur on the AC networks at each end, this means that property rights can be assigned over the link on a 'contract path' basis. A strict 'use-it-or-lose-it' rule was applied to prevent generators buying up capacity to prevent access, pricing was transparent as auction results were published on the internet shortly after they 
closed, and no user could gain priority over another except by offering a higher bid price. Capacity on DC interconnectors between Nordel-UCTE was not auctioned, though occasional bilateral trades are thought to have occurred during 2001 in which equity holders leased capacity to other users, but prices were not reported publicly.

The Nord Pool had developed an implicit auction mechanism that linked the spot market for electricity, with transmission capacity. This, so called, 'market splitting' mechanism involved the following steps:

i. Generators submitted prices and quantity pairs at which they are prepared to supply electricity, for each hour of the next day, to the Nord Pool;

ii. A clearing price was established across the entire Nord Pool, for each hour, at which supply equalled demand, assuming no transmission constraints;

iii. If transmission constraints made the dispatch of plant infeasible the market was split with the price at the side of the constraint where generation is in deficit progressively raised, and where generation was in surplus progressively lowered, until supply, and demand, each side of the constraint were satisfied;

iv. The merchandising surplus across the constraint was retained by the TSOs.

Any difference that arose between spot prices in different Nord Pool locations therefore represented the value of transmission congestion between them. As the congestion increased so did the difference in the prices between two locations. The issue of loop flow was automatically dealt with by the Nord Pool auction mechanism because it related spot prices to transmission costs in a single step, rather than attempting to separately value congestion on particular transmission lines, or transmission routes. Not only did the Nord Pool implicit auction mechanism reduce transaction costs, and neatly deal with the loop flow issue, but the EC also believed that it was superior to the explicit auctions, as employed between other European locations, because:

One problem emerging with explicit auctions is that they allow generators to bid different prices in different spot markets. This gives them the opportunity to segment markets and preserve price differences that would result in the absence of interconnection [EC, 2001b]. 


\subsection{European Commission Proposals}

The EC proposed a series of amendments to the ED (EC 2001a, EC 2001d) that aimed to complete the single European electricity market by 2005 including:

$i$. speeding up supply competition so that all industrial consumers free to choose their electricity supplier by 2003 , and gas supplier by 2004 , with consumers of all sizes free to choose both their electricity and gas supplier by 2005 ;

ii. $\quad$ separating the management of transmission, distribution, supply and generation;

iii. establishing an independent energy regulatory function in each country; and

$i v$. ensuring non-discriminatory access to networks via transparent, published, tariffs.

The lack of sufficient transmission capacity between countries, inefficiency in the pricing mechanisms that were being used to allocate that scarce capacity, and the congestion that occurred as a result had all been identified as major barriers to the development of crossborder trade. The EC therefore also sought reforms to the way in which cross-border trade in electricity was conducted by proposing that:

$i$ a common set of network access tariffs, technical access rules, available transfer capacity definitions, and congestion management methods, on crossborder transmission capacity, should be agreed by the end of 2003 ;

ii. a new infrastructure plan be adopted, under the TENS initiative, that would aim to relieve capacity constraints on seven key European cross-border electricity (and five gas) transmission routes, and allow up to $20 \%$ of the investment cost to be met from central EU funds;

iii. reciprocal market opening measures be adopted that would allow the European market to be opened up to cross-border trade with third countries, subject to reciprocal access agreements, compliance with EU environmental standards, and safeguards relating to nuclear plant.

Although agreement could only be reached to open supply competition to all industrial consumers, with a minimum of $60 \%$ of each national market eligible to supply competition by 2004 . The remaining proposals on wholesale market reform were adopted in full (European Council, 2002). 
By the end of 2001, the EC appears to have formed the view that the gradual introduction of supply competition was not going to be sufficient to bring about a competitive single European electricity market at the retail level, because of the highly concentrated, vertically integrated, nature of the industry in many EU countries, which reduced competition at the wholesale level. Guaranteeing non-discriminatory access to existing transmission capacity, and encouraging investment in new transmission capacity to relieve constraints, were seen as the new mechanisms that would complete the single European electricity market, curtail generator market power in the wholesale market, and ultimately deliver lower prices to consumers in the retail market. The EC's basic thesis seems to have been that even if regulatory authorities in every EU country allowed a generating monopoly to be created within their jurisdiction, this could be rendered irrelevant if access could be guaranteed to sufficient cross-border transmission capacity. The EC clearly believed that the threat of entry, via open access to the European transmission network, would be sufficient to force even national monopoly generating firms to behave as if they were in a competitive single European electricity market, rather than fifteen isolated national markets.

\section{ANALYSIS}

The emergence of new exchange traded wholesale electricity markets, coupled with increasing liquidity, allowed reliable wholesale electricity price data, covering most of the major EU electricity markets, except France, to be assembled for the first time in 2001. In this section, the single European electricity market is analysed at the wholesale level by applying a range of statistical, and econometric, techniques to mean spot (day-ahead) electricity prices from all the European wholesale electricity exchanges operating during 2001.

\subsection{Wholesale Locational Spot Market Prices}

Time series containing mean daily electricity prices $\left(\mathrm{P}_{\mathrm{t}}\right)$ traded on a day-ahead basis for delivery $^{5}$ on the 365 days of 2001 were collected for 15 European locations in Norway, Sweden, Denmark, Finland, England \& Wales, Spain, Netherlands, and Germany. Where necessary, prices were converted to a common $€ / M W h$ value using the exchange rate

\footnotetext{
${ }^{5}$ Simple arithmetic average of 24 hourly or 48 half-hourly settlement prices for next day (day-ahead) delivery, as published by the exchange. Prices are not demand weighted.
} 
prevailing at close of business on the delivery date except for weekends and holidays where the rate from the previous working day was used. Table 1 summarises the wholesale markets analysed in this paper, delivery locations, data treatment, and sources.

Table 1: Time series data

\begin{tabular}{|c|c|c|c|c|c|c|}
\hline Location (Country) & TSO & Market Operator & Website & Base Currency & Report Currency & Day-Ahead Delivery Date \\
\hline Norway (Osio) & NORDEL & \multirow{10}{*}{ Nord Pool } & \multirow{10}{*}{ mww.nordpool.no } & NOK & EUR & 01 Jan - 31 Dec \\
\hline Norway (Bergen) & NORDEL & & & NOK & EUR & 01 Jan - 31 Dec \\
\hline Norway (Kristiansand) & NORDEL & & & NOK & EUR & 01 Jan - 31 Dec \\
\hline Norway (Trondheim) & NORDEL & & & NOK & EUR & 01 Jan - 31 Dec \\
\hline Nonway (Tromso) & NORDEL & & & NOK & EUR & 01 Jan - 31 Dec \\
\hline Sweden (Stockholm) & NORDEL & & & SEK & EUR & 01 Jan - 31 Dec \\
\hline Finland (Helsinki) & NORDEL & & & FiM & EUR & 01 Jan - 31 Dec \\
\hline E Denmark (Copenhagen) & NORDEL & & & DKK & EUR & 01 Jan - 31 Dec \\
\hline W Denmark (Odense) & NORDEL & & & DiKK & $\overline{E U R}$ & 01 Jan - 31 Dec \\
\hline Nord Pool (System) & NORDEL & & & NOK & EUR & 01 Jan - 31 Dec \\
\hline \multirow{2}{*}{ Eng \& Wales (System) } & \multirow{2}{*}{ UKTOA } & Pool & www.elecpool.co.uk & GBP & EUR & $01 \mathrm{Jan}$ - $26 \mathrm{Mar}$ \\
\hline & & UKPX & www.ukpx.co.uk & GBP & EUR & 27 Mar - 31 Dec \\
\hline Spain (System) & UCTE & Omel & www.comel.es & ESP & EUR & 01 Jan - 31 Dec \\
\hline German EEX (System) & UCTE & EEX & www.eex.de & DEM & EUR & 01 Jan - 31 Dec \\
\hline German LPX (System) & UCTE & LPX & www.lpx.de & DEM & EUR & $01 \mathrm{Jan}$ - 31 Dec \\
\hline Netherlands (System) & UCTE & $A P X$ & wmw.apx.nl & NLG & EUR & 01 Jan-31 Dec \\
\hline
\end{tabular}

Table 2 contains summary statistics, which show that daily day-ahead wholesale electricity prices differed widely between different locations across Europe, during 2001. Price volatility was also very high with a price range of over $500 \%$ of mean annual levels at some locations. A qualitative analysis of the data, from the chart in Figure 5, confirms that European wholesale spot electricity prices not only varied widely between different geographic locations, but also that regular 'price spikes' occurred throughout 2001. As a result, prices appear to have diverged between pairs of locations, sometimes by several hundred $€ / \mathrm{MWh}$ (e.g. Netherlands - Germany), and then rapidly converged again over a matter of a few days.

Table 2: Summary statistics for daily locational prices

\begin{tabular}{|c|c|c|c|c|c|c|c|}
\hline LOCATION & Mean & $\begin{array}{c}\text { Standard } \\
\text { Error }\end{array}$ & Median & $\begin{array}{c}\text { Standard } \\
\text { Deviation }\end{array}$ & Range & Minimum & Maximum \\
\hline Norway (Oslo) & 23.61 & 0.26 & 22.95 & 4.94 & 44.06 & 13.34 & 57.41 \\
\hline Norway (Bergen) & 23.09 & 0.26 & 22.57 & 4.88 & 63.15 & 13.87 & 77.01 \\
\hline Norway (Kristiansand) & 23.10 & 0.26 & 22.57 & 4.89 & 63.15 & 13.87 & 77.01 \\
\hline Norway (Trondheim) & 23.47 & 0.25 & 22.77 & 4.71 & 61.95 & 15.36 & 77.31 \\
\hline Norway (Tromso) & 23.42 & 0.24 & 22.78 & 4.66 & 61.95 & 15.36 & 77.31 \\
\hline Sweden (Stockholm) & 22.82 & 0.27 & 22.52 & 5.20 & 65.75 & 11.34 & 77.09 \\
\hline Finland (Helsinki) & 22.82 & 0.27 & 22.47 & 5.19 & 66.03 & 11.31 & 77.34 \\
\hline E Denmark (Copenhagen) & 23.49 & 0.29 & 23.25 & 5.63 & 66.00 & 11.31 & 77.31 \\
\hline W Denmark (Odense) & 23.64 & 0.26 & 23.05 & 4.97 & 44.07 & 13.34 & 57.41 \\
\hline Nord Pool (System) & 23.15 & 0.25 & 22.65 & 4.87 & 62.25 & 14.96 & 77.21 \\
\hline Eng \& Wales (System) & 28.36 & 0.23 & 27.98 & 4.46 & 31.81 & 11.57 & 43.38 \\
\hline Spain Comel (System) & 30.94 & 0.57 & 28.85 & 10.90 & 55.49 & 11.13 & 66.62 \\
\hline Germany EEX (System) & 24.52 & 0.94 & 22.97 & 17.92 & 274.39 & 8.29 & 282.68 \\
\hline Germany LPX (System) & 24.07 & 0.82 & 22.31 & 15.70 & 234.96 & 5.30 & 240.26 \\
\hline Netherlands (System) & 33.46 & 1.42 & 27.23 & 27.20 & 261.09 & 2.05 & 263.14 \\
\hline
\end{tabular}




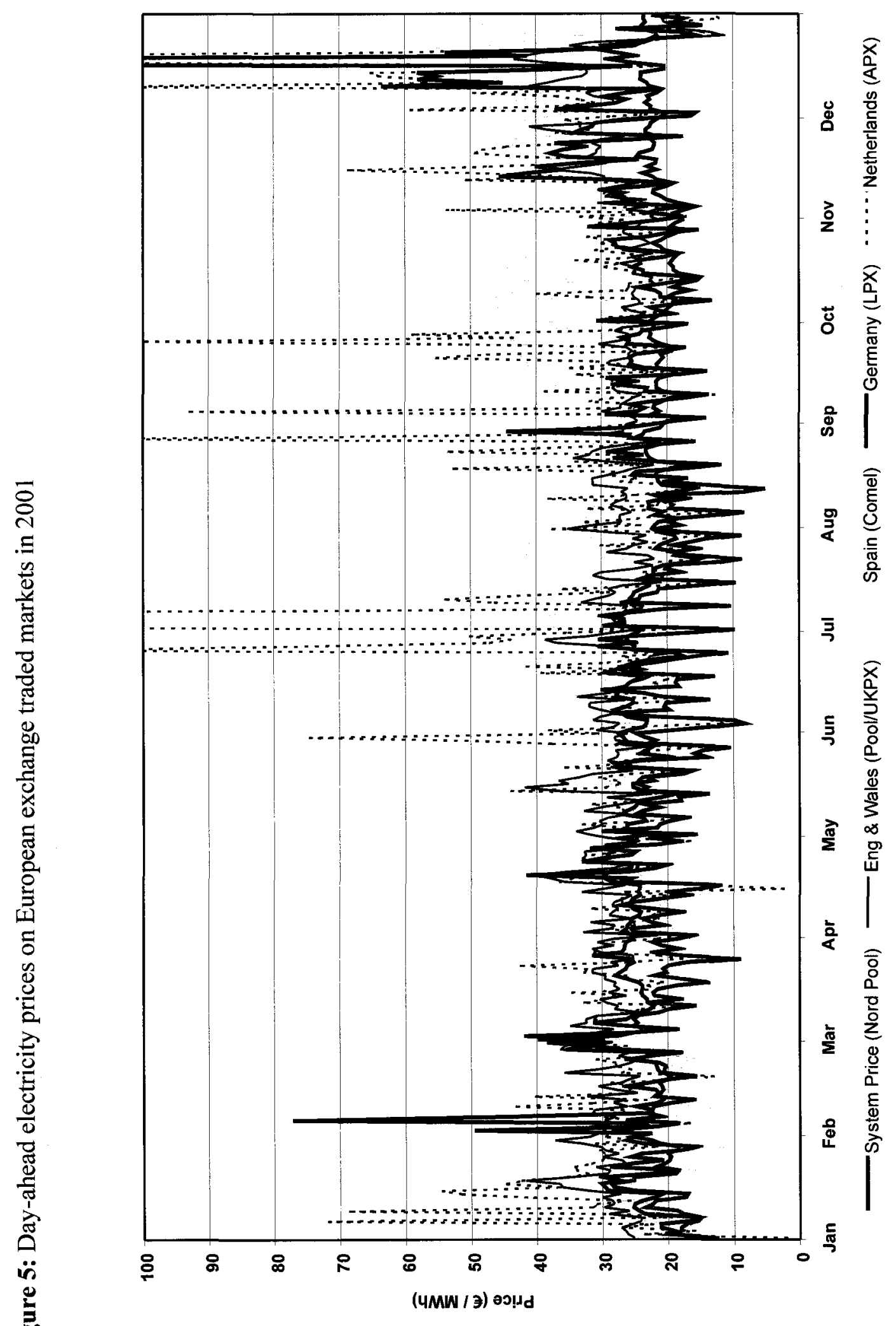




\subsection{Correlation Analysis of Locational Price Changes}

New time series, each containing 364 daily price changes, were produced by taking first differences of the original locational price time series. In other words, by taking the mean daily price $\left(P_{t}\right)$ and subtracting mean daily price from the previous day $\left(P_{t-1}\right)$ as in Formula 1.

$$
\Delta P_{t}=P_{t}-P_{t-1}
$$

A correlation matrix was then produced from the new series, as shown in Table 3 . Where the correlation coefficient is close to unity, this indicates that spot prices in the pair of locations tended to move up and down by the same amount of $€ / \mathrm{MWh}$ on any given day. Likewise, where the correlation coefficient is close to zero this indicates that a spot price change in one location was not generally reflected in a change in spot price at the other location. This analysis reveals that, in Nord Pool, price changes in one location were, in general, highly correlated with price changes in all other Nord Pool locations, as indicated by correlation coefficients above 0.7 . The correlation between Nord Pool spot price changes, and those in other locations, is significantly lower and generally below 0.2 . This means that day-today supply, or demand, shocks in one Nord Pool location tended to simultaneously induce a change in wholesale electricity prices for all other Nord Pool locations, and of a similar magnitude. In contrast, the price impact of a shock in locations outside Nord Pool tended to remain isolated in one wholesale market, and not affect prices in other locations.

\subsection{Cointegration Analysis of Locational Spot Prices}

An alternative analytical technique that can be used to analyse the relationship between market prices in different locations is cointegration analysis [see Verbeek, (2000) for a short introduction and Hendry \& Juselius (2000) and Hendry \& Juselius (2001) for a more comprehensive discussion]. This technique has been widely used in analysing relationships between a wide range of economic time series including spot and futures prices in oil markets Gulen (1998), in locational spot natural gas markets Walls (1994), De-Vany \& Walls (1993), 
locational spot electricity markets, Woo et al (1997), and between spot markets for different types of fuel, Yucel \& Guo (1994).

The basic idea is that if two markets are cointegrated then there will be a long-run equilibrium relationship between their price time series. Utilising ordinary least squares (OLS) regression, the technique seeks to estimate the cointegrating regression parameters as set out in Formula 2.

$$
P_{i=\alpha}+\beta P_{j}+\mu
$$

Engle \& Granger (1987) suggest a two-stage procedure; first estimate the parameters of the cointegrating regression to specify the long-run equilibrium between the time series, then use the parameters estimated to calculate the residual errors, $\mu$ and test these for stationarity. Spurious (nonsense) regression results, characterised by high $\mathrm{R}^{2}$, and high autocorrelated residuals, are generally obtained whenever trending economic time series are regressed against each other. However, in the case of cointegrated price time series, as is the case here, this does not occur because even though the two price time series may exhibit non stationary random walk $I(1)$ behaviour typical of a commodity or financial market, the linear combination of the two price time series that a cointegrating regression produces will be stationary $I(0)$. In other words, if two price time series are cointegrated, the non stationarity in one will offset some or all of the non stationarity in the other series.

As before, $P_{i}$ represents daily day-ahead electricity prices in the notional import location, $P_{j}$ represents daily day-ahead electricity prices in the notional export location. The constant term, $\alpha$, represents the equilibrium level of the transmission price, $\beta$ represents the cointegrating parameter which will be equal to one if the two sets of market prices are perfectly cointegrated, and $\mu$ is the residual error term of the cointegrating regression that represents the periodtoperiod dispersion of the locational spread around the long-run equilibrium. If the two price time series are cointegrated then the residuals from the regression will be stationary $I(0)$, and fluctuate around zero, indicating that there is an equilibrium relationship between wholesale market prices in the pair of locations. If the two price time series are not cointegrated, then the residual from the regression will be non-stationary $I(1)$, and zero crossings will be infrequent, indicating that 
no long-run equilibrium relationship exists. Testing for stationarity in the residuals is therefore crucial, as it is this that confirms whether or not the two locational price time series are cointegrated. Dickey \& Fuller (1979) developed a statistical test for this purpose, which was later improved upon, and it is this augmented Dickey Fuller (ADF) test that is used here.

Results from the cointegration analysis of the locational market price time series described above are presented in Table 4. These show that locational wholesale market prices, throughout Nord Pool, were strongly cointegrated during 2001. This is indicated by the ADF statistic of less than the critical values (-3.944), meaning that the null hypothesis of non-cointegration can be rejected at the $1 \%$ level for every pair of locations. Both the German EEX, and LPX, markets appear to be well cointegrated with markets in Sweden, Finland, and Denmark. However, they are poorly cointegrated with Norway, which may be due to the lack of a direct physical connection between the two countries. Somewhat surprisingly, given the relative lack of physical connection capacity to mainland Europe, prices in England \& Wales do appear to be well cointegrated with prices in Nord Pool, Netherlands, and Germany. Span appears to be poorly integrated with any other European location, as might be expected by its peripheral location, and limited cross-border transmission capacity. Pairs of locations that are not cointegrated, are defined as those where the null hypothesis of non-cointegration cannot be rejected, even at the $10 \%$ level, denoted by grey shading in Table 4.

These results therefore indicate that there were robust long-run equilibrium relationships between all pairs of locational spot prices within Nord Pool, and between many Nord Pool locations, and locations outside Scandinavia, during 2001. In general, where both locations were outside Nord Pool there was a weaker cointegration relationship, though still statistically significant. Most notable among these is the Netherlands, though having the highest mean prices, and also the greatest volatility, the market does appear to be well integrated with most Nord Pool locations, England \& Wales, and both German markets. 


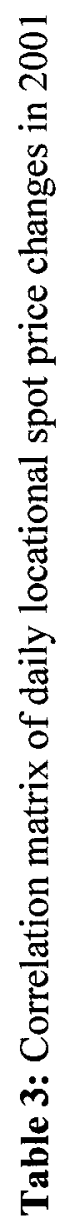

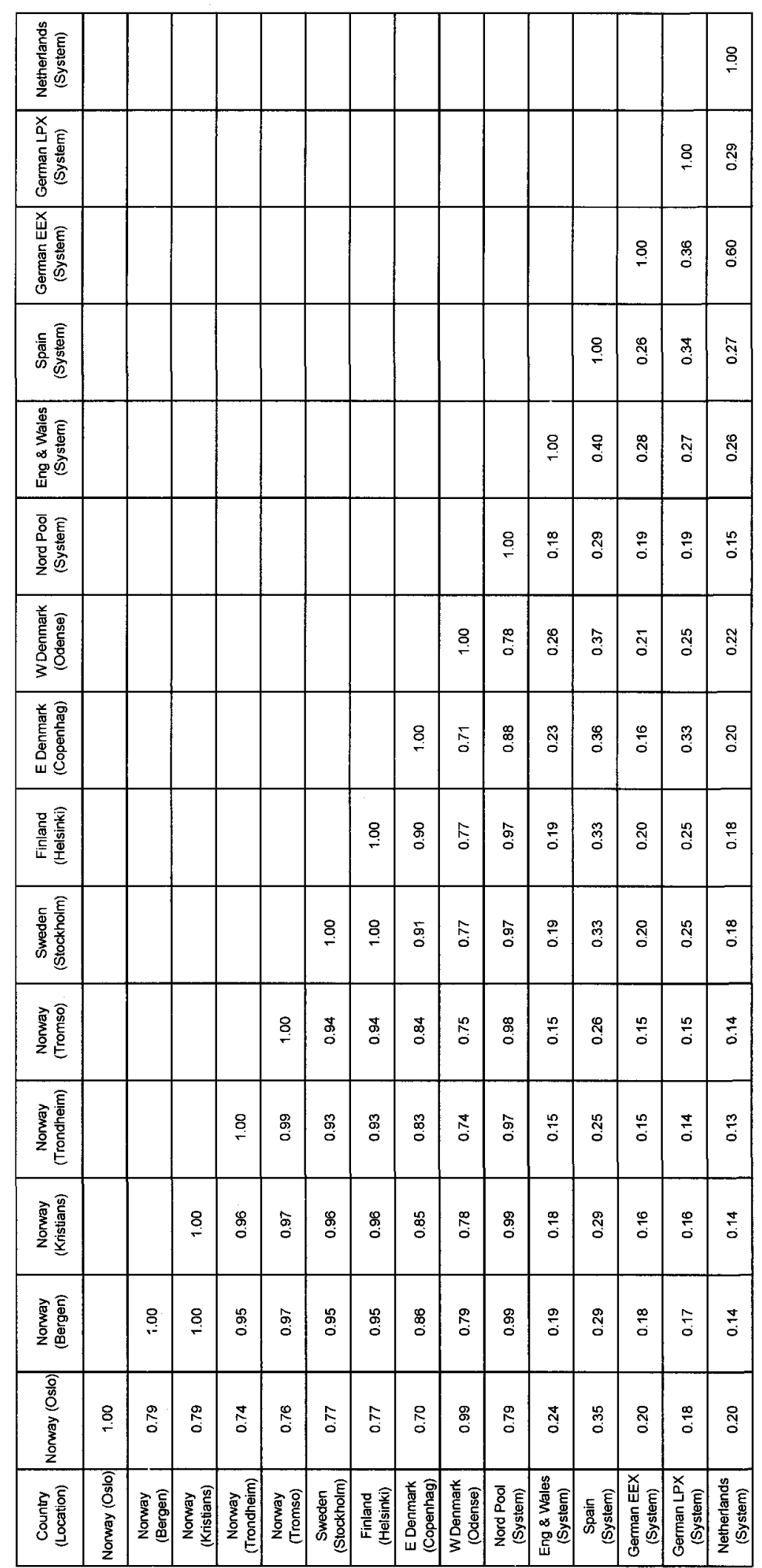




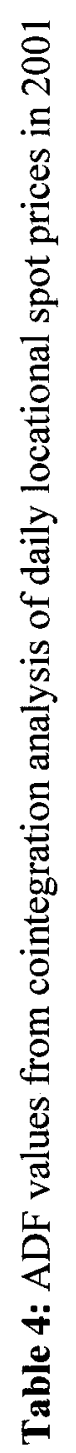

\begin{tabular}{|c|c|c|c|c|c|c|c|c|c|c|c|c|c|c|}
\hline 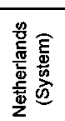 & & & & & & & & & & & & & & \\
\hline 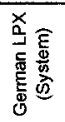 & & & & & & & & & & & & & & ז̊ํㅇ \\
\hline 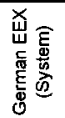 & & & & & & & & & & & & & $\overline{\mathcal{H}}$ & 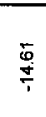 \\
\hline 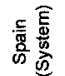 & & & & & & & & & & & & 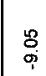 & \begin{tabular}{|l|} 
\\
$\stackrel{\circ}{\%}$
\end{tabular} & 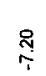 \\
\hline 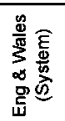 & & & & & & & & & & & $\stackrel{\circ}{-}$ & 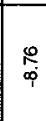 & 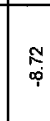 & $\begin{array}{l}\text { F } \\
\text { of }\end{array}$ \\
\hline 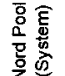 & & & & & & & & & & \begin{tabular}{l}
$\infty$ \\
\hdashline \\
0
\end{tabular} & $\stackrel{2}{\longrightarrow}$ & 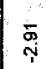 & 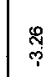 & શ્ণ \\
\hline 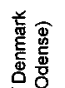 & & & & & & & & & 恕 & 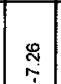 & 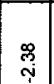 & $\mid \frac{8}{8}$ & $\stackrel{8}{9}$ & 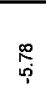 \\
\hline 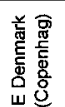 & & & & & & & . & ఫุ & 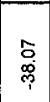 & 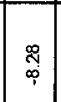 & $\underset{T}{T}$ & \begin{tabular}{l}
$\mathscr{8}$ \\
\hdashline \\
\hdashline
\end{tabular} & $\hat{\overline{0}}$ & 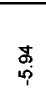 \\
\hline 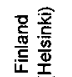 & & & & & & & 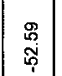 & \begin{tabular}{|l}
$\mathscr{8}$ \\
\multirow{7}{*}{$\mid$}
\end{tabular} & 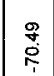 & 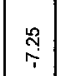 & $\stackrel{\circ}{\circ}$ & $\frac{n}{4}$ & 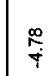 & 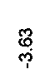 \\
\hline 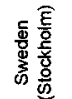 & & & & & & 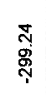 & 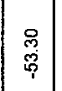 & $\mid$\begin{tabular}{c}
$\mathscr{7}$ \\
\multirow{\Im}{*}{$\mid$}
\end{tabular} & 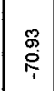 & $\mid \begin{array}{l}0 \\
\end{array}$ & 움 & $\frac{m}{q}$ & $\stackrel{\substack{f \\
f}}{q}$ & $\stackrel{\mathscr{ஜ}}{\%}$ \\
\hline 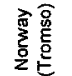 & & & & & 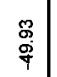 & 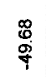 & 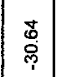 & 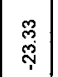 & $\begin{array}{c}\text { 古 } \\
\text { o. }\end{array}$ & 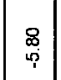 & 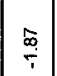 & ד & ষ্ণ & $\stackrel{\mathscr{B}}{\longrightarrow}$ \\
\hline 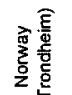 & & & & 品 & 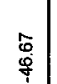 & 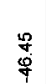 & 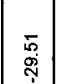 & 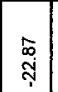 & 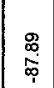 & $\begin{array}{c}2 \\
2 \\
0 \\
10\end{array}$ & ì & $\stackrel{\square}{\square}$ & $\stackrel{\mathbb{m}}{\sim}$ & $\stackrel{\text { of }}{\rightarrow}$ \\
\hline 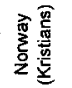 & & . & 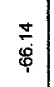 & $\begin{array}{c}\text { o } \\
\stackrel{0}{0}\end{array}$ & 壳 & 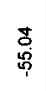 & \begin{tabular}{|c|c|} 
\\
$⿱ 亠 䒑$ \\
\hdashline
\end{tabular} & 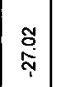 & 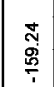 & $\begin{array}{l}\mathbf{T} \\
\dot{\phi}\end{array}$ & $\stackrel{8}{-1}$ & 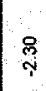 & זָ & $\stackrel{?}{\text { S }}$ \\
\hline 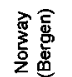 & & 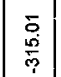 & 总 & 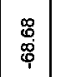 & 芯 & 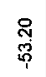 & $\underset{\tilde{p}}{\bar{p}}$ & 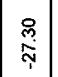 & 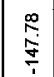 & : & $F$ & $\stackrel{\mathbb{B}}{\mathrm{S}}$ & ฟ్ & 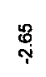 \\
\hline 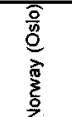 & 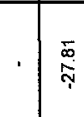 & 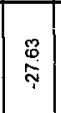 & 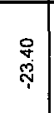 & 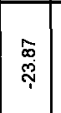 & 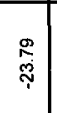 & $\underset{\substack{0 \\
\tilde{\gamma}}}{ }$ & 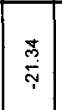 & 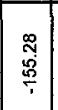 & 怘 & 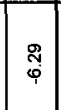 & $\underset{\varpi}{ \pm}$ & 8 & $\stackrel{g}{9}$ & $\begin{array}{l}\infty \\
\stackrel{8}{i}\end{array}$ \\
\hline 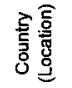 & & & & & & & & & & & & & & \\
\hline
\end{tabular}

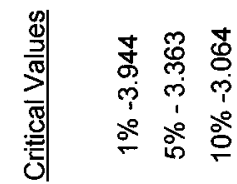
2 


\section{DISCUSSION}

Arbitrage is the mechanism that will ultimately create the single European electricity market. Put simply if generators, traders, supply companies, and consumers have a legally enforceable right to generate (or purchase) electricity at one European location, and deliver it via the transmission system for consumption (or sale) at another European location, then spot (and forward) markets across Europe will become fully integrated. Arbitrage is crucial because it increases economic efficiency by allowing generators in disparate geographic locations, which would otherwise be operating in economically isolated markets, to compete with one another to supply consumers in any other market. In the remainder of this section, results from the analysis presented above are examined for evidence that arbitrage did occur between European locations during 2001, and its impact on the efficiency of locational spot prices, and the price of transmission capacity between locations, is quantified. First, the relationship between locational spot prices, and the price of transmission capacity, is defined.

\subsection{Locational Spot Price Model}

Hogan (1992) develops the theme of locational spot prices as means of allocating scarce transmission capacity. Based on the work of Bohn et al (1984) and Schweppe et al (1988) the concept of economic efficiency lies at its core:

\footnotetext{
The availability of short run prices could provide a powerful tool for guiding the use of the electric power system. The theory of spot pricing identifies the competitive price at each bus (location). Efficient transmission of power from one bus to another would not be priced at anything higher than the difference in the spot prices at the respective buses [Hogan (1992), 213)]
}

The concept of a single European electricity market can therefore be defined in terms of a fundamental arbitrage relationship in which spot prices at one location, $P_{i}$, should equal the spot price at another location $P_{j}$ plus the price of transmission between them, $\mathrm{T}_{i j}$, as per Formula 3.

$$
T_{i j}=P_{i}-P_{j}
$$


Given this arbitrage relationship then the transmission price between two locations should be equal to the difference in the locational spot prices. Where locational prices are equal, then the price of transmission between them should be zero. The price of transmission is made up of a congestion charge, $T_{C i j}$, which equals the rental value of transmission capacity between two locations, plus the incremental effect on system losses of transmitting electricity between two locations, $T_{L i j}$ as denoted by Formula 4 .

$$
T_{i j}=T_{C i j}+T_{L i j}
$$

The congestion charge is equal to the opportunity cost of using the capacity. Therefore, if demand for transmission capacity is less than the available transmission capacity between two locations, assuming that TSO is prevented from withholding capacity, the congestion charge, $T_{C i j}$, should equal zero.

If an economically efficient single European electricity market had been operating at the wholesale level, during 2001, then the model presented above should have held, and the results presented in the previous section should evidence the following characteristic behaviour:

i. $\quad$ spot prices would have been equal to the marginal cost of production at each location;

ii. if spot prices differed between locations that difference would have equalled the difference in the marginal cost of generation at each location;

iii. if spot prices differed between a pair of locations, that difference should have been equal to the price of transmission capacity between them;

iv. if transmission capacity was congested, between a pair of locations, the transmission price should have been equal to the opportunity cost of using that congested capacity, plus the cost of transmission losses, and

$v$. if transmission capacity was not congested between a pair of locations, the transmission price should have equalled the cost of transmission losses only.

The locational spot price model described above is consistent with operation of the Law of One Price since if the price of transmission is zero then prices in a pair of locations will be identical. The model also satisfies what has come to be known as the no arbitrage condition; 
in other words if the price in a pair of locations is exactly equal then no arbitrage opportunity exists. In practical terms, this means that no net flow of electricity should occur between locations, even if the transmission line is uncongested, and the price of congestion is zero. If a trader were to enter into a transaction that caused a net flow this would result in a transmission loss, and an associated cost that could not be covered by the price difference between the two locations. Indeed, it would be profitable for another trader to enter into an exactly equal, and opposite, transaction that would offset the flow, reduce transmission losses to zero, and thereby collect the saved cost of transmission losses as an arbitrage profit.

\subsection{Evidence of Arbitrage From Physical Constraints and Flows}

The values in Table 2 reveal that there were significant price differences between some European locations resulting in potential arbitrage opportunities. To the extent that a persistent price difference occurred between locations this should give rise to persistent transmission congestion, leading from the low priced to high priced locations. The reason for this is because generators, traders, supply firms, and consumers will rush to take advantage of the arbitrage opportunity, so increasing demand for transmission capacity, that can only be satisfied if the clearing price for transmission congestion rises to equilibrate demand and supply. This is exactly what appears to be occurring France $\rightarrow$ UK and on the other heavily congested routes identified earlier in this paper. Physical flows, although not necessarily coincident with contractual flows, were also from low priced to high priced location (UCTE 2002). For example, the ratio of flows France $\rightarrow$ UK versus $U K \rightarrow$ France during 2001 was $53: 1$. Similarly the ratio of flows Germany $\rightarrow$ Netherlands versus Netherlands $\rightarrow$ Germany during 2001 was $44: 1$.

Where there is no persistent price difference between a pair of locations then there should have been no persistent transmission congestion, though intermittent arbitrage opportunities, and intermittent congestion in both directions could still occur throughout the year. As previously identified in this report intermittent congestion occurs in both directions on the Germany $\leftrightarrow$ Denmark route. For example, the ratio of net physical Denmark $\rightarrow$ Germany versus Germany $\rightarrow$ Denmark was $2: 1$. This is much closer to parity than the previous examples given, reflecting the fact that German prices were, on average, slightly higher than in Denmark. 
Although a comprehensive set of locational spot prices was not available for the whole of Europe, the coincidence of the direction of major price differences, transmission constraints, and physical flows indicates that arbitrage trades were occurring between locations and in the direction indicated by the price difference seen throughout the year.

\subsection{Evidence of Arbitrage from Correlation and Cointegration}

The correlation, and cointegration, analysis described above measures different aspects of the arbitrage relationship between prices at different locations. For Nord Pool locations the strong price change correlation, and cointegration of price levels, indicates that arbitrage was ensuring that prices essentially rise, and fall, in lock step, and if they did diverge they did so only occasionally, and then rapidly reconverged.

At the other extreme, there was little correlation, or cointegration, between prices in Spain and other markets. The poor correlation of price changes means that prices in Spain tended to frequently diverge, from the levels in the rest of Europe, and the results from the cointegration analysis suggest that once prices had diverged they tended not to revert back to any well established equilibrium level. There therefore appears to have been no effective arbitrage process connecting Spain to other European electricity markets during 2001.

The remaining European locations appeared to be in the middle ground exhibiting strong price cointegration, but weak price change correlation, with other locations including Nord Pool. Here prices are clearly not responding to supply and demand shocks by exactly the same amount, in the short run, but nor were they diverging in the long run either. This behaviour is, however, still consistent with an arbitrage process occurring between locations. The reason that prices were poorly correlated between these pairs of locations is because transmission constraints caused the relevant locational spot markets to disintegrate. Once a constraint has occurred, a price rise on either side of the constraint can have no impact on the price at the other side. Any change in prices of the two locations can only be reflected in a change in the price of congestion. Unless a shock relieves the constraint, and reduces the price of congestion to zero, the pair of locational spot prices will rise, and fall, independently of each other. Once the constraint has been relieved the pair of prices will once again move in lock step. The results of the correlation, and cointegration analysis are therefore consistent with the locational spot price model described above. It also carries with it an important 
conclusion about the nature of the single European electricity market. Significant price differences between pairs of locations, poor price correlation, and transmission constraints do not mean that arbitrage, in the form of cross-border trade, was not occurring in 2001. Indeed, transmission constraints are strong evidence that trade was occurring, and that insufficient capacity was available to carry all the trade that would need to occur in order to equilibrate prices between a pair of locations.

\subsection{Efficiency in Locational Spot Prices}

From the statistical analysis of the locational spot price time series, presented in Table 1, it is clear that wholesale electricity prices, in common with retail prices, differed markedly between European locations throughout 2001. The lowest wholesale price was in the Nord Pool System at around $€ 23.50 / \mathrm{MWh}$, followed by Germany, UK, Spain, and highest in the Netherlands at $€ 33.46$. However, the fact that prices varied between locations does not of itself indicate economic inefficiency, or the absence of a single European electricity market, since locational price differences may reflect differences in marginal production costs, transmission constraints, and or transmission losses. The amount by which spot prices exceed the opportunity cost of electricity at a given location is a precise measure of economic inefficiency. The opportunity cost is either the marginal cost of generation, at a given location, or the marginal cost of generation at another location plus the transmission cost from that location.

Table 5 estimates the Lerner ${ }^{6}$ Index for each wholesale market location assuming the marginal unit of generating capacity for the whole of Europe was a conventional coal-fired power plant, burning imported coal, and that no transmission constraints occurred, hence the cost of transmission between all locations was zero. Recall that in a perfectly competitive market, the Lerner index will equal zero. Though, in practice, the identity of the marginal generating unit at each location would have changed with time of day, and season, a thermal efficiency of $33 \%$ is assumed. This is somewhat lower than the mean thermal efficiency of the coal-fired plant fleet operating across the EU; for example, in the United Kingdom the mean thermal efficiency of all coal plant was $37.5 \%$, and for the most modern units, operating continuously in baseload mode, $40 \%$ thermal efficiency was feasible. On the basis

\footnotetext{
${ }^{6}$ Lerner Index $=($ Price - Marginal Cost $) /$ Marginal cost and is essentially a measure of the percentage mark up of prices over marginal cost with a theoretical range between $0 \rightarrow 1$.
} 
of this analysis it appears that generators in Nord Pool, and Germany, were selling electricity at prices that were close to their marginal opportunity cost. The fact that mean annual locational spot prices in Nord Pool, and Germany, also fall within a $€ 1 / \mathrm{MWh}$ range of each other, indicates that any differences were likely to have been due to slight variations in marginal generation costs, and transmission costs.

Though, on a given day much larger spot price differences did occur between locations, than mean prices suggest, any exercise of market power was temporary. As far as economic efficiency is concerned, Scandinavian countries in Nord Pool, and Germany, therefore appear to meet the perfect competition criterion. In contrast, the Lerner Index for Spain, UK, and Netherlands indicates that prices were well above the completive level. Since generators in these locations regularly accessed international markets for supplies of competitively priced coal, during 2001, and operated modern coal-fired plant, this indicates that they were able to exercise significant market power. The $€ 10 / \mathrm{MWh}$ range in mean locational spot prices, across all the European locations tested is also too wide to be explained by a difference in marginal generation costs between locations. The Lerner Index provides a direct measure of the loss of efficiency, due to the exercise of market power, which is approximately zero for Nord Pool, and Germany, and rises as high as $29 \%$ for the Netherlands.

\subsection{Efficiency in Pricing of Transmission Congestion}

The locational spot price model is well suited to analysing transmission costs in the heavily interconnected networks of Europe because it does not require flows, and capacities, on individual transmission lines to be identified, and therefore avoids the need to address the issue of loop flow. Given that there are over 250 cross-border transmission interconnections between UCTE countries alone, and many tens of thousands more within them, the complexity of attempting a link-based analysis, on individual transmission lines, such as that proposed by Chao \& Peck (1996), would be overwhelming. To estimate the theoretical congestion charge, between the locations tested, the raw price data described above was transformed to produce new time series containing 365 mean daily locational price differences, $T_{i j}$. These were calculated by notionally designating each location in turn as an export location, and subtracting its mean daily price, $P_{j}$, from the mean daily prices in each of the remaining locations, $P_{i}$, notionally designated as import locations. This calculation is consistent with the locational spot price model set out above. 
The mean, and mean absolute deviation (MAD) of the congestion charge between each pair of notional import-export locations, for the whole of 2001, has been calculated with the results presented in Table 6 . Where the congestion charge is positive then this indicates that the price in the notional import location was usually greater than the notional export location, and vice versa. The ratio of MAD to mean indicates the extent, and the direction in which transmission congestion occurred between pairs of locations. Where both the mean, and $\mathrm{MAD}$, are close to zero this either indicates that only minor price transmission constraints occurred between a pair of locations, or if major differences occurred they were infrequent (e.g. Oslo-Stockholm). A large positive (or negative) mean, combined with a slightly greater $\mathrm{MAD}$, indicates that transmission constraints frequently occurred, and consistently in one direction (Netherlands - Germany LPX). A mean close to zero, combined with a significantly large MAD, indicates transmission constraints frequently occurred between a pair of locations but not consistently in one direction (e.g. German LPX - Nord Pool).

A striking pattern emerges from this analysis, which is that where at least one of a pair of locations is outside Nord Pool, the Mean and MAD is approximately one order of magnitude higher than where both locations are within Nord Pool. This suggests that locational price differences were greater between locations outside Nord Pool, than within it, and or occurred more frequently. Within Nord Pool the ratio of mean to MAD is almost always greater than three, but where at least one location is outside Nord Pool the ratio is usually close to one. This suggests that price differences between pairs of Nord Pool locations must either reverse, or fall to zero, more frequently than do price differences between locations outside Nord Pool.

Table 7 contains estimates of the actual cost, paid by generators and consumers, incurred in transmitting power between locations in 2001. It is composed of three elements:

i. Import charge levied by local TSO

ii. Export charge levied by local TSO

iii. Congestion charge from explicit, or implicit, transmission capacity auctions. 


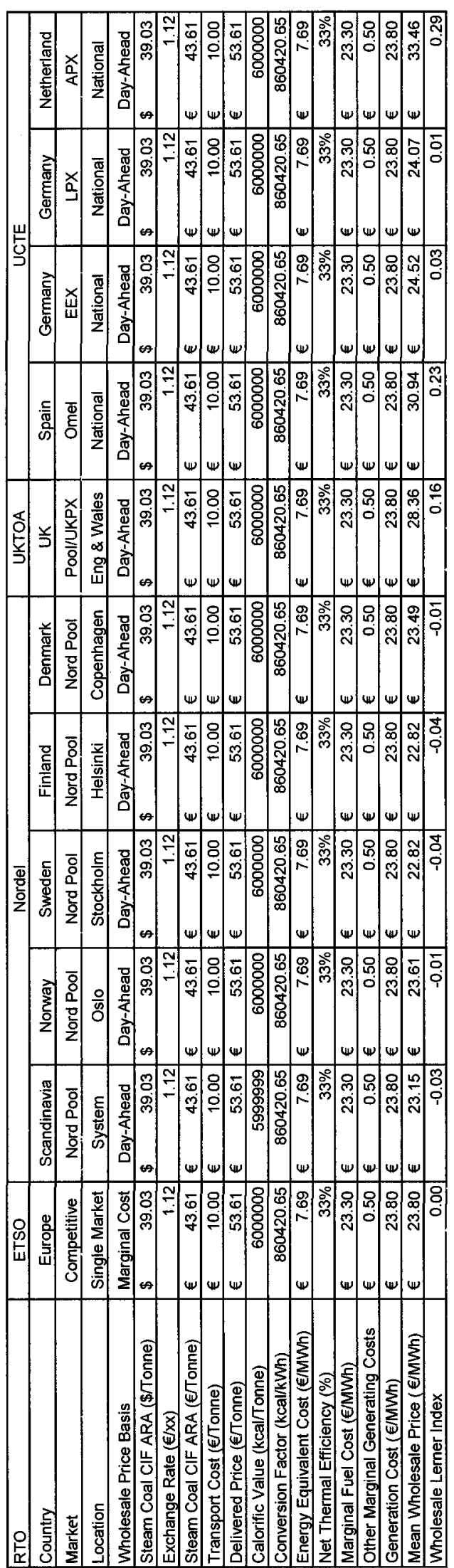




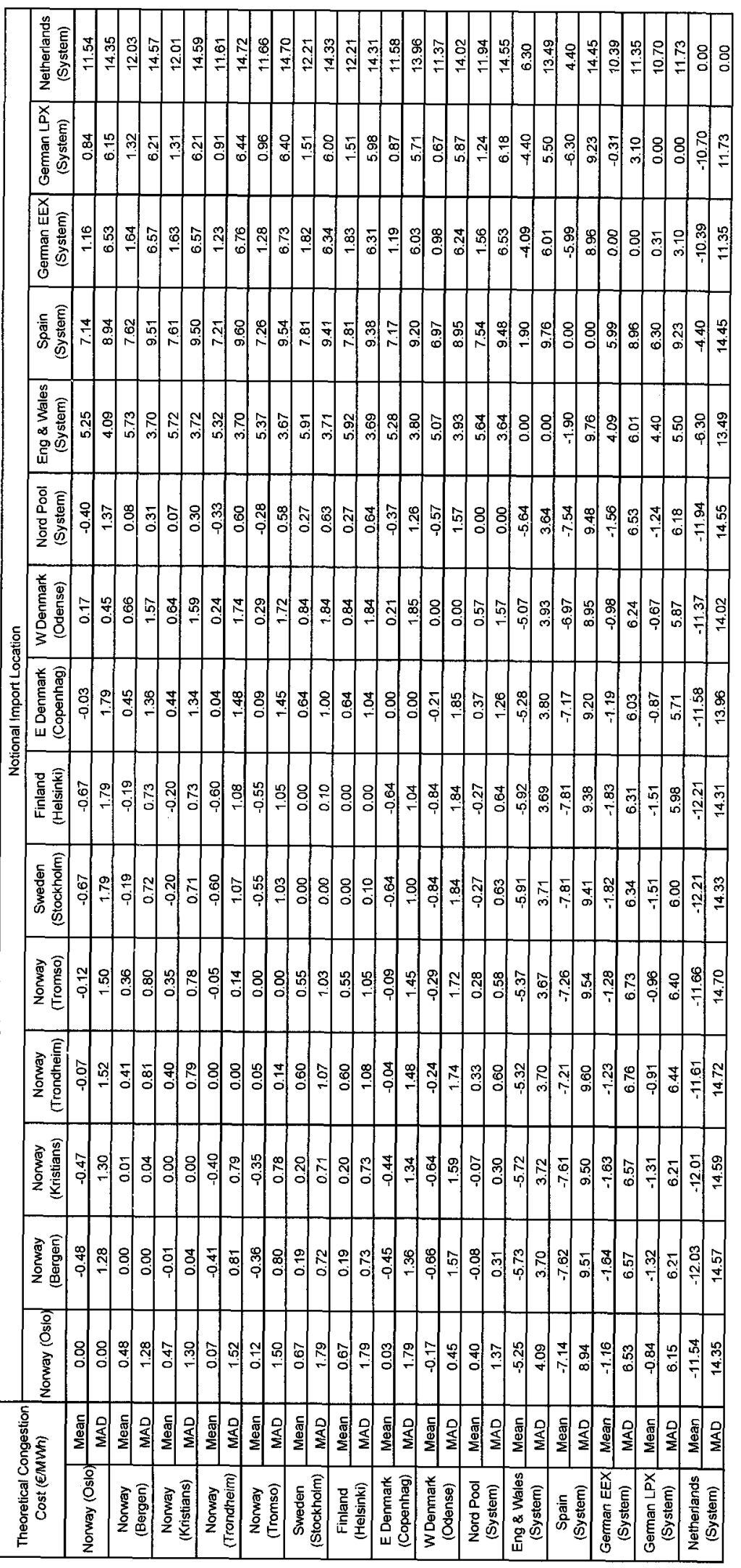



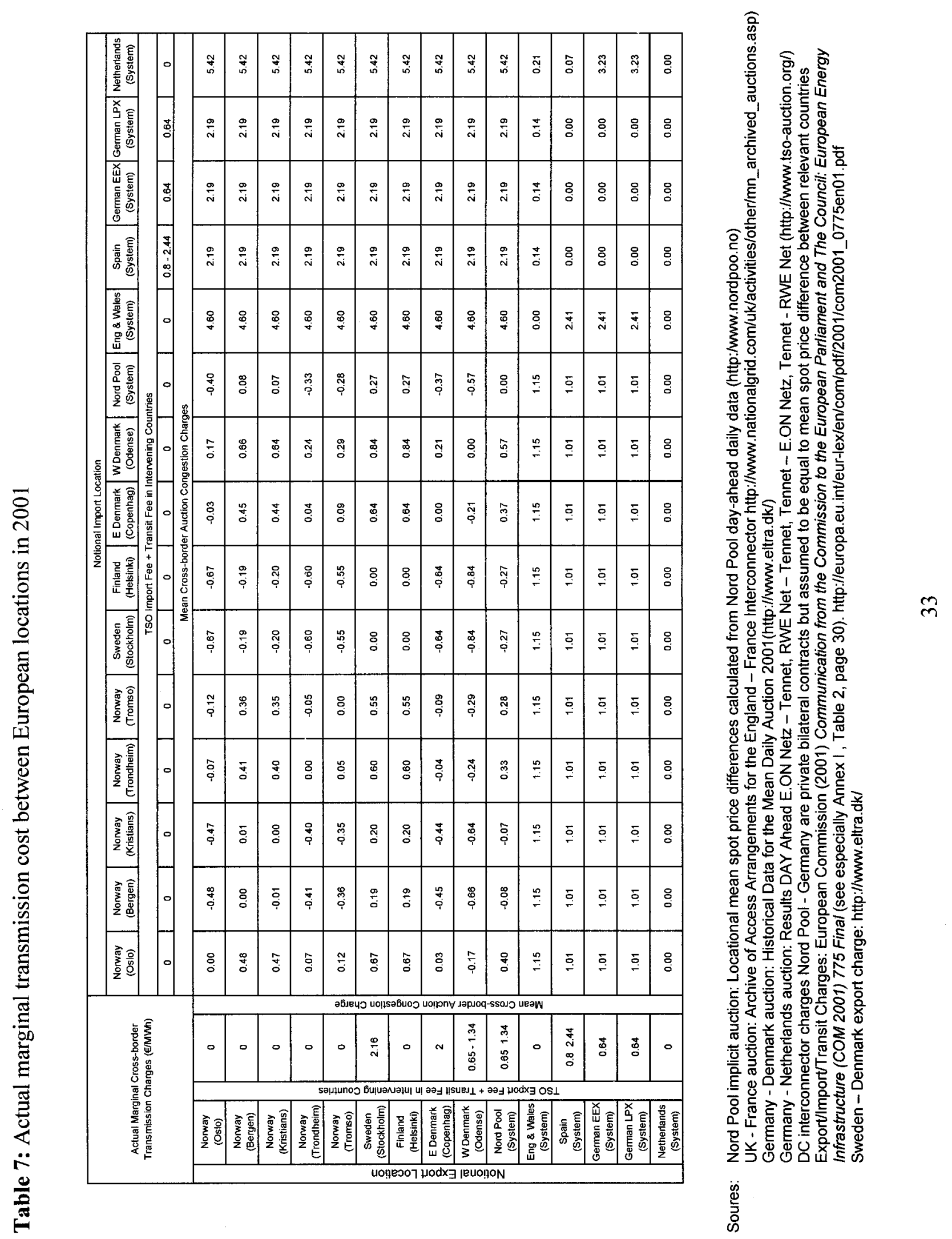
The ETSO compromise proposal, coming into force on 1 March 2002, replaced the import, and export, charges levied by individual TSOs. Instead generators paid $€ 1 / \mathrm{MWh}$ to a central fund on declared export volumes. Consumers paid a socialised $€ 1 / \mathrm{MWh}$ charge on the net physical import flow into each country. Though rates would no longer be pancaked, the addition of an arbitrary $€ 1 / \mathrm{MWh}$ to all exports, and socialising a further $€ 1 / \mathrm{MWh}$ on imports does nothing to increase efficiency in transmission pricing. Generators, and consumers also continued to pay transmission tariffs to their local TSO, to cover the infrastructure cost of the transmission network, and managing its operation, as they had always done.

A survey commissioned by the EC (Comilas, 2002), attempted to estimate the full cost of transmission within EU countries covered by ETSO during 2000. This was estimated for generators, and consumers, and decomposed into: a Fixed charge that does not vary with output, a Capacity charge related to the maximum injection, or withdrawal, that can be made at each transmission connection point, and an Energy charge that varies with the amount of electricity produced by generators, or used by consumers. Excluding regulatory charges, for example compensation for stranded assets, the total transmission cost component of the retail price for a large industrial consumer purchasing electricity, produced within their own country, varied between $€ 10.36 / \mathrm{MWh}$ (Spain), and $€ 2.98$ (Sweden). However, with the possible exception of the variable cost in Nord Pool countries, none of these values represents the marginal cost of transmitting electricity between two locations in Europe, arising as a result of congestion, or transmission losses. The reason being that, with minor exceptions, they do not vary bylocation, or by time period, and were socialised across all users.

If an efficient single European electricity market had been operating in 2001 the values in Table 6 , representing the theoretical price of congestion, and Table 7 representing the actual price being charged by European TSOs should have been equal. To the extent that they are not, this indicates the inefficiency that remains in pricing of transmission congestion in Europe. In general, it appears to have been most efficient between Nord Pool locations, because of the market splitting mechanism employed, which should achieve an identical outcome to the locational spot price model described above. 
The explicit auction mechanisms used to allocate cross-border transmission capacity elsewhere in Europe did not produce an efficient outcome in AC transmission networks because they underestimate the impact of congestion on lines outside the contract path, and overestimate it on lines along the contract path. The contract path method only prices capaity efficiently on the DC links between RTO networks, as parallel flows do not occur on DC lines. Further inefficiency occurs because available capacity was either not auctioned at all, because it was reserved for long-term contracts signed before the ED came into force, because excessive amounts of capacity were reserved for reliability purposes, or as in the case of the UKFrance interconnector a reserve price on the auction meant that capacity remained unsold whenever the price of congestion fell below the reserve price. In all these cases, otherwise profitable arbitrage trading opportunities were left unexploited because of weaknesses in the capacity allocation mechanism. To the extent that these arbitrage trades did not take place, and locational pricedifferences (price of transmission congestion) were larger than they would otherwise have been, then this is a source of inefficiency.

The biggest divergence between the actual marginal cost of transmission congestion, in Table 6 , and the values, in Table 7, occurred between the Netherlands and Germany. This appears to give credibility to anecdotal evidence that in the Belgium-Netherlands-Germany case, incumbent generators were, in certain circumstances, purchasing capacity and then leaving it unused to prevent entry by competitive supplies. Although a use it or lose it rule applied on month-ahead, and yearly auctions, any capacity which was declared unwanted on a dayahead basis could not be auctioned off to other potential users. In effect, transmission capacity which had a positive congestion value was withdrawn from the market, and combined with the priority allocation of capacity to long-term contracts, almost certainly resulted in higher prices in the Netherlands than would have otherwise occurred.

Overall, generators actually paid less for transmission capacity on the Germany $\rightarrow$ Netherlands route than the theoretical calculation, based on locational spot prices suggests they should have paid. The loss of efficiency that arose as a result of the TSO import-export tariffs, and inefficiency in the congestion management auction, on this transmission route amounted to approximately $€ 6.50 / \mathrm{MWh}$, or $20 \%$ of the mean annual price in the Netherlands. Slightly smaller 
losses of efficiency occurred between Nord Pool locations, and Netherlands. The loss of efficiency between other European locations was considerably less than this, and was close to zero, between pairs of Nord Pool locations.

\subsection{Efficiency in Pricing Transmission Losses}

The cost of transmission losses, which generally amounts to approximately $2-3 \%$ of electricity generated, ${ }^{7}$ is excluded from Table 6 and Table 7. In most EU countries, transmission losses are socialised by applying a variable energy uplift charge that multiplies the cost of the electricity consumed by a percentage equal to expected total transmission losses. This uplift charge does not generally vary by location, though transmission losses in Norway were calculated algorithmically, and applied on a zonal basis, by multiplying the loss factor by the marginal price at each location. In Finland, generators were required to physically compensate losses by increasing generation output. The magnitude of incremental losses created by cross-border trade, between countries, during 2001 is unknown. ETSO had no plans to address the issue. However, the magnitude of the impact on efficiency can be estimated from values published for England \& Wales, by the National Grid Company. Total transmission losses amounted to $1.8 \%$ of winter peak demand, but NGC estimated that adding $1 \mathrm{MWh}$ of incremental generation output in the north of England, where there was a generation capacity surplus, had an incremental impact of $0.95 \mathrm{MWh}$ on the electricity available for consumption in the south of England where there was a generation deficit. In other words the marginal cost of transmission losses between the north and south were approximately $5 \%$ of marginal generation costs. Therefore, socialising the cost across the country is expected to give rise to loss of efficiency of $0-3 \%$ of marginal generation costs or approximately $€ 0-0.75 / \mathrm{MWh}$, depending on the pair of locations concerned. Though no EU country was allocating transmission losses in an economically efficient way during 2001, its impact on efficiency was an order of magnitude less important than that created by the exercise of generator market power.

\footnotetext{
${ }^{7}$ A further 6-7\% may be lost as a result of transforming electricity to lower voltages for, and subsequent transportation through, the distribution system. This is not considered here but is usually socialised as proportional uplift to the price paid by consumers either on a national, or a regional basis.
} 


\section{IMPLICATIONS}

The EC proposal to complete the single European electricity market, as at the end of 2001, was essentially composed of two elements. In the short term, increasing the efficiency of pricing mechanisms being used to allocate scarce transmission capacity, and in the long term, increasing total amount of transmission capacity. These proposals are examined in the light of the findings presented above.

\subsection{Increasing the Efficiency of Transmission Pricing Mechanisms}

The empirical observation is that the Nord Pool market splitting mechanism produces true locational spot prices, and actual transmission congestion charges that are identical to the theoretical values. However, Bjørndal \& Jørnsten (2001) criticise Nord Pool for moving away from true locational spot pricing, during 2001, to a system in which prices are determined for predefined zones based on the a priori judgment of the TSOs about the most likely location of transmission constraints. To the extent that congestion occurred within these predefined zones, this introduced a degree of market inefficiency that was not present before 2001 .

The current explicit auctions of transmission capacity on the AC networks of Europe are inefficient because they do not take account of parallel flows. This threatens system security, because it means that generators, and consumers, are not given the correct price signals about the marginal value of generation and load at each location. Implementing a market splitting mechanism in each of the five European TSOs should not be any more complex than implementing it in the Nordel system. If implemented without predefining zones, then efficient transmission congestion prices would emerge without further intervention. The allocation of transmission losses is a second order issue, the magnitude of which would be further reduced by implementing a more efficient transmission pricing mechanism that reduced the incidence of transmission constraints.

Explicit auctions should still be used on DC links between RTO networks but the entire capacity must be made available to all potential users, on a non discriminatory basis. The exercise of 
market power by monopoly TSO owners must be regulated to prevent capacity from being arbitrarily constrained, either through withdrawal of the capacity on offer, or the setting of minimum reserve prices. Current use-it-or-loseit principles should be extended to all time periods including day-ahead auctions to prevent incumbent generators creating artificial transmission constraints.

\subsection{Transmission Investment}

The fact that generating firms are able to exercise market power at different times, to different degrees, and at different locations explains why persistent locational spot prices differences occurred across Europe during 2001.

The EC believes that if sufficient transmission capacity could be built, and access guaranteed, then locational spot prices differences, and the transmission congestion that they reflect would largely disappear. However, precisely the same result would be achieved if a sufficiently large number of firms were competing at each European location, so as to ensure a competitive spot market. Taken to the ultimate extreme, if sufficient transmission capacity could be built to take account of all potential shocks to the supply, and demand, prices would never diverge between locations again. Moreover, prices would always be at the competitive level, and would only fluctuate in line with the marginal production cost of the marginal plant operating for the whole of Europe.

In practice, the EC already had sufficient regulatory powers to force divestment of generating capacity, or break up firms with dominant positions in individual national markets, to increase competition by 2001 . If it used these powers aggressively, the wholesale price of electricity would quickly fall to marginal generation cost at each European location. Net flows between pairs of locations would only occur if the difference in marginal generation costs exceeded the cost of transmission losses. Demand for transmission capacity would fall, hence relieving constraints and rendering unnecessary the building of new capacity. 
Though the end result may be the same, the cost of building a large amount of transmission capacity in order to relieve constraints between locations, versus using existing regulatory powers to increase competition at locations where generators are able to exercise market power, is significantly different. This is no better exemplified than by one of the seven priority electricity transmission project themes, identified by the EC. A feasibility study was completed in 2001 that proposed building a single 1320 MW capacity DC cable from Norway to theUK, beginning in 2002, and completing in 2006, at a total budgeted cost of $€ 750$ million. At around the same time, a $2000 \mathrm{MW}$ capacity coal-fired generation plant was sold for $€ 600$ million by an incumbent generator wishing to exit the UK market. The regulatoy, legal, banking, and other advisory costs associated with selling this generating capacity would have amounted to approximately $2 \%$ of the transaction value, or $€ 12$ million. The investment cost of building the Norway-UK cable will therefore be almost 100 times greater, per MW of capacity, than the incremental expenses associated with divesting generating capacity. Moreover, even if the Norway-UK cable had begun construction in 2002, it would still have taken ten years to plan, and build, while the sale of a generating plant was completed in a matter of months.

The EC proposal to complete the single European electricity market, as it currently stood at the end of 2001, did not address the central issue, which was that the generation sector in many EU countries is highly concentrated. To invest public money in relieving constraints, especially in cross-border transmission capacity, while failing to use existing regulatory powers to reduce industry concentration in the generation sector, made little economic sense. Since the planning and construction of sufficient transmission capacity to reduce prices to competitive levels in the wholesale market take years, or even decades, longer to implement than generation capacity divestment, this was at odds with the deadline that the EC aimed to achieve for introducing supply competition in the retail market, for all consumers, by 2005 . 


\section{REFERENCES}

Bergman, L., Brunekreeft, G. Doyle, C.,von der Fehr, NH. M., Newbery, D. M., Politt, Vaitilingham, R. (Ed) (1999) $A$ European Market for Electricity: Monitoring European Deregulation. Centre for Economic Policy Research, London www.cepr.org and SNS, Stockholm www.sns.se. ISBN: 1898128421

Bjørndal, M., Jørnsten, K. (2001) “Zonal Pricing in a Deregulated Electricity Market”, Energy Journal, Vol. 22, No. 1, pp. 51 73

Bohn, R. E., Caramanis M. C., Schweppe, F. .C. (1984) "Optimal Pricing in Electrical Networks Over Space and Time", The Rand Journal of Economics Vol. 18, No. 3

Cameron (2002) Competition in Energy Markets: Law and Regulation in the European Union. Oxford University Press. ISBN 0$19-825770-8$

Chao, H-P, Peck, S. (1996) “A Market Mechanism For Electric Power Transmission", Journal of Regulatory Economics, Vol. 10, pp. 25-59.

Cini, M., McGowan, L., (1998) Competition Policy in the European Union (see especially pp. 169 - 175), The European Union Series. MacMillan Press Ltd., London.

Comilas (2002) Benchmark of Electricity Transmission Tariffs: Final Report: February 2002

http://europa.eu.int/comm/energy/en/elec_single_market/btt/bench_trans_tarif.pdf

De Vany, A., Walls, D. W., (1993) "Pipeline Access and Market Integration in the Natural Gas Industry: Evidence from Cointegration Tests". Energy Journal. Vol. 14, No. 4, pp. 1-19.

Dickey, D. A., Fuller, W. A. (1979) "Distribution of Estimators for autoregressive time series with a unit root" Journal of the American Statistical Association Vol. 74, pp. $427-431$

EC (1988) Working Document: Internal Energy Market http://europa.eu.int/comm/energy

EC (1995) For a European Union Energy Policy - Green Paper COM (94)65

EC (2000) Opening Up to Choice: The Single Electricity Market

http://europa.eu.int/comm/energy/en/elec_single_market/elecbro.pdf

EC (2001a) Communication from the Commission to the Council and the European Parliament: Completing the Internal Energy Market (presented by the Commission) (COM 2001) Final

EC (2001b) Commission Staff Working Paper: First Report on the implementation of the internal electricity and gas market 3.12.2001 SEC (2001) 1957. http://europa.eu.int/comm/energy/en/internal-market/library/reporten.pdf

EC (2001c) Report from the Commission to the Council, the European Parliament, the Economic and Social Committee, and the Committee of the Regions on the implementation of the guidelines for Trans-European Energy Networks in the period 1996-2001. (Draft) 14.12.2001. http://europa.eu.int/comm/energy/library/report-infraen.pdf

EC (2001d) Proposal for a European Parliament and Council Decision amending Decision No 1254/96/EC laying down a series of Guidelines for trans-European energy networks (Draft) 18.12.2001. http://europa.eu.int/comm/energy/library/propositioninfra-en.pdf

EC (2001d) Communication from the Commission to the European Parliament and Council: Energy Infrastructure COM (2001) 775. (Final) 20.12.2001. http://europa.eu.int/eur-lex/en/com/pdf/2001/com2001_0775en01.pdf

EERF (2000a) Conclusions: Fifth Meeting of the European Electricity Regulation Forum, Florence 30-31 March 2000. http://europa.eu.int/comm/energy/en/elec_single_market/florence/fl_concl_5_en.pdf

EERF (2000b) Conclusions: Sixth Meeting of the European Electricity Regulation Forum, Florence 9-10 November 2000. http://europa.eu.int/comm/energy/en/elec_single_market/florence/6thconclusionsfinal.pdf 
EERF (2001) Conclusions: Seventh Meeting of the European Electricity Regulation Forum, May 2001 $\mathrm{http}: / /$ europa.eu.int/comm/energy/en/elec_single_market/florence/6thconclusionsfinal.pdf

EERF (2002a) Discussion Paper: The 2003 Cross-border Tarrification Mechanism $\mathrm{http}$ ://europa.eu.int/comm/energy/en/elec_single_market/florence-8/disc-compensation.pdf

EERF (2002b) Discussion Paper: Congestion Management http://europa.eu.int/comm/energy/en/elec_single_market/florence8/disc-congestion.pdf

EERF (2002c) Conclusions: Eighth Meeting of the European Electricity Regulation Forum, Florence 21 -22 February 2002 $\mathrm{http} / /$ europa.eu.int/comm/energy/en/elec_single_market/florence-8/final-concl.pdf

Engle, R. F., Granger, C. W. J. (1987) "Cointegration and error correction: Representation, estimation, and testing" Econometrica Vol. 55, pp. $251-276$

ETSO (1999) Evaluation of Congestion Management Methods for Cross-Border Transmission November 1999. http://www.etso-net.org/media/download/

ETSO (2000) Cross-border Tariffs for the Internal Market of Electricity in Europe (IEM) 19 September 2000. http://www.etsonet.org/media/download/

ETSO (2001 a) Key Concepts and Definitions for Transmission Access Products: Final Report April 2001. http://www.etsonet.org/media/download/

ETSO (2001a) Coordinated Use of Power Exchanges for Congestion Management: Final Report April 2001. http://www.etsonet.org/media/download/

ETSO (2001b) Definitions of Transfer Capacities in Liberalised Electricity Markets: Final Report. 2001. http://www.etsonet.org/media/download/

ETSO (2001c) Coordinated Use of Power Exchanges for Congestion Management: Final Report: April 2001 http://www.etso-net.org/media/download/

ETSO (2001d) ETSO Proposal for a Temporary Cross-border Tariff Mechanism 3 September 2001 http://www.etso-net.org/media/download/

ETSO (2002) Reconciliation of Market Splitting with co-ordinated auction concepts. Technical Issues. Draft Discussion. Paper February 2002

European Council (2002) Presidency Conclusions: Barcelona European Council. 15 - 16 March 2002.

http://ue.eu.int/en/Info/eurocouncil/index.htm

EU (1988) Single European Act (OJ 1987 L169/29/6).

EU (1990a) Directive 90/377/EEC Price Transparency Directive (OJ 1990 L185/1)

EU (1990b) Directive 90/547/EEC Electricity Transit Directive (OJ 1990 L313/30)

EU (1991) Directive 91/296/EEC Gas Transit Directive (OJ 1991 L147/37)

EU (1996a) EP and Council Decision No 1254/96/EC of 5 June 1996 Trans European Network Directive (OJ L 161 1997

L27/20)

EU (1996b) Directive 96/926/EC Electricity Directive (OJ 1997 L27/20)

EU (1998) Directive 98/30/EC Gas Directive (OJ 1998 L204/1)

Gulen, S. G., (1998) "Efficiency in the Crude Oil Futures Market", Journal of Energy Finance and Development, Vol. 3. No. 1, pp. $13-21$.

Hendry, D. F., Juselius, K. (2000) “Explaining Cointegration Analysis: Part I”, Energy Journal, Vol. 21, No 1., pp. 1 - 42 
Hendry, D. F., Juselius, K. (2001) “Explaining Cointegration Analysis: Part II”, Energy Journal, Vol. 22, No 1., pp. 75 - 120

Hogan (1992) "Contract Networks for Electric Power Transmission”, Journal of Regulatory Economics, Vol. 4, pp. 211 - 242.

Hunt, S., and Shuttleworth, G. (1996) Competition and Choice in Electricity. National Economic Research Associates, John Wiley \& Sons. ISBN 0-471-95782-8

IAEW/Consentec (2001) Analysis of Electricity Network Capacities and Identification of Congestion. Final Report: December 2001. http://europa.eu.int/comm/energy/en/elec_single_market/harm_rep/

Joskow, P. L., and Schmalensee, R. (1983) Markets for Power: An Analysis of Electric Utility Deregulation. The MIT Press. Cambridge MA. ASIN: 0262100282

Schweppe, F. C., Caramanis, M.C., Tabors, R.D., Bohn, R.E. (1988) Spot Pricing of Electricity, Norwell, MA; Kluwer Academic Publishers

UCTE (2002) Statistics: Physical Electricity Exchanges 2001 http://www.ucte.org/pdf/statistics/Exchange/e_exchange_2001.pdf

Verbeek, M. (2000) A Guide to Modern Econometrics, Wiley, Chichester, England. ISBN: 0-471-89982-8

Walls, D. W. (1994) "Price Convergence Across Natural Gas Fields and City Markets", Energy Journal, Vol. 15, No. 4, pp. 37 48 .

Woo, C-K., Lloyd-Zanetti, D., Horowitz, I. (1997) “Electricity Market Cointegration in the Pacific Northwest”, Energy Journal, Vol. 18 , No.3, pp. $75-101$.

Yucel, M. K., Guo, S. (1994) “Fuel Taxes and Cointegration of Energy Prices”, Contemporary Economic Policy, Vol. 12, No. 3, pp. $33-41$. 
OXFORD INSTITUTE FOR ENERGY STUDIES

57 WOODSTOCK ROAD, OXFORD OX2 6FA ENGLAND

TELEPHONE (01865) 311377

FAX (01865) 310527

E-mail: publications@oxfordenergy.org

http://www.oxfordenergy.org 